\title{
BROOKHFWEN
}

NATIONAL LABORATORY

BNL-99764-2013-IR

\section{Effect of Shim Arm Depletion in the NBSR}

A.L. Hanson, N.R. Brown, D.J. Diamond

February 2013

\author{
Nuclear Science \& Technology Department \\ Brookhaven National Laboratory
}

\author{
U.S. Department of Energy \\ National Institute of Science \& Technology
}

Notice: This manuscript has been authored by employees of Brookhaven Science Associates, LLC under Contract No. DE-AC02-98CH10886 with the U.S. Department of Energy. The publisher by accepting the manuscript for publication acknowledges that the United States Government retains a non-exclusive, paid-up, irrevocable, world-wide license to publish or reproduce the published form of this manuscript, or allow others to do so, for United States Government purposes. 


\section{DISCLAIMER}

This report was prepared as an account of work sponsored by an agency of the United States Government. Neither the United States Government nor any agency thereof, nor any of their employees, nor any of their contractors, subcontractors, or their employees, makes any warranty, express or implied, or assumes any legal liability or responsibility for the accuracy, completeness, or any third party's use or the results of such use of any information, apparatus, product, or process disclosed, or represents that its use would not infringe privately owned rights. Reference herein to any specific commercial product, process, or service by trade name, trademark, manufacturer, or otherwise, does not necessarily constitute or imply its endorsement, recommendation, or favoring by the United States Government or any agency thereof or its contractors or subcontractors. The views and opinions of authors expressed herein do not necessarily state or reflect those of the United States Government or any agency thereof. 
BNL-99764-2013-IR

\section{Effect of Shim Arm Depletion in the NBSR}

Manuscript Completed:

February 21, 2013

Prepared by:

A.L. Hanson, N.R. Brown, D.J. Diamond

Nuclear Science \& Technology Department

Brookhaven National Laboratory

Upton, NY 11973-5000

Prepared for:

National Institute of Science \& Technology

National Nuclear Security Administration 


\section{Abstract}

The cadmium shim arms in the NBSR undergo burnup during reactor operation and hence, require periodic replacement. Presently, the shim arms are replaced after every 25 cycles to guarantee they can maintain sufficient shutdown margin. Two prior reports document the expected change in the ${ }^{113} \mathrm{Cd}$ distribution because of the shim arm depletion. One set of calculations was for the present high-enriched uranium fuel and the other for the low-enriched uranium fuel when it was in the COMP7 configuration (7 inch fuel length vs. the present 11 inch length). The depleted ${ }^{113} \mathrm{Cd}$ distributions calculated for these cores were applied to the current design for an equilibrium lowenriched uranium core. This report details the predicted effects, if any, of shim arm depletion on the shim arm worth, the shutdown margin, power distributions, and kinetics parameters. 


\section{Table of Contents}

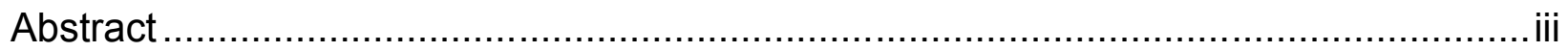

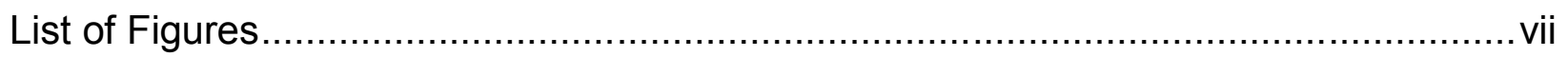

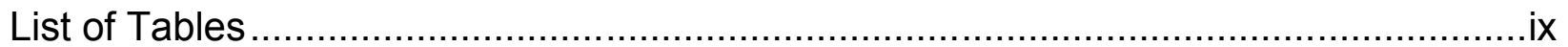

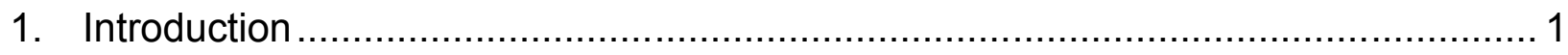

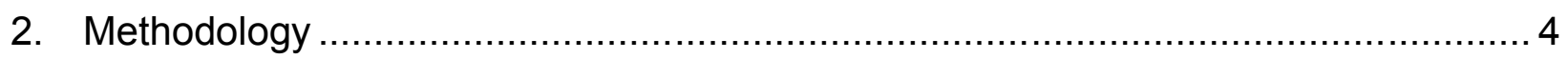

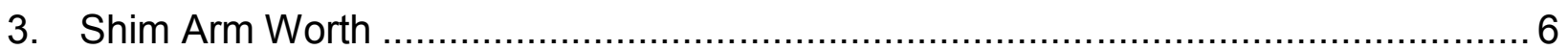

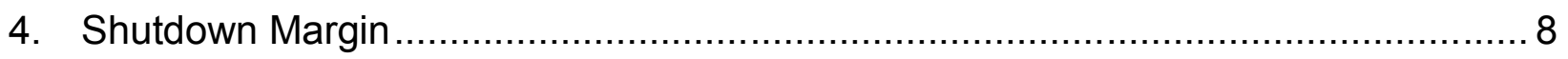

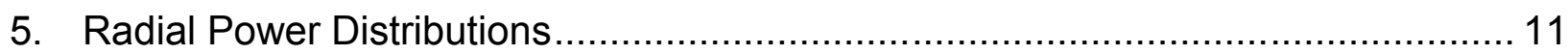

6. Three Dimensional Power Distributions ................................................................ 20

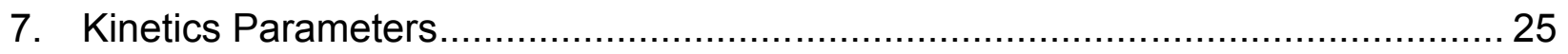

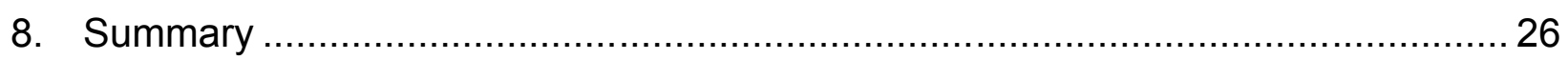

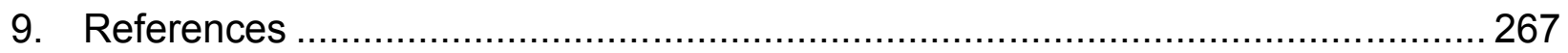




\section{List of Figures}

Figure 1. Vertical cross section of the NBSR at the location of the \#2 Shim Arm. ....................... 2

Figure 2. Horizontal cross section of the NBSR at the mid-plane of the reactor........................... 3

Figure 3. Element Position Designation ........................................................................................... 3

Figure 4. Shutdown margin 1: The value of $K_{\text {eff }}$ at SU for the HEU and LEU cores with the DSA (HEU and LEU) and C7DSA distributions when Shim Arm \#1 is withdrawn and the other three are inserted.

Figure 5. Shutdown margin 2: The value of $\mathrm{K}_{\text {eff }}$ at SU for the HEU and LEU cores with the DSA (HEU and LEU) and C7DSA distributions when Shim Arm \#2 is withdrawn and the other three are inserted.

Figure 6. Shutdown margin 3: The value of $\mathrm{K}_{\text {eff }}$ at SU for the HEU and LEU cores with the DSA (HEU and LEU) and C7DSA distributions when Shim Arm \#3 is withdrawn and the other three are inserted.

Figure 7. Shutdown margin 4: The value of $\mathrm{K}_{\text {eff }}$ at SU for the HEU and LEU cores with the DSA (HEU and LEU) and C7DSA distributions when Shim Arm \#4 is withdrawn and the other three are inserted.

Figure 8. Radial power distribution for the upper half of the core for a.) HEU SU, b.)HEU SU DSA and c.) The percentage differences between the HEU SU and the HEU SU DSA ............12 Figure 9. Radial power distribution for the lower half of the core for a.) HEU SU, b.)HEU SU DSA and c.) The percentage differences between the HEU SU and the HEU SU DSA ............13 Figure 10. Radial power distribution for the upper half of the core for a.) HEU EOC, b.)HEU EOC DSA and c.) The percentage differences between the HEU EOC and the HEU EOC DSA

Figure 11. Radial power distribution for the lower half of the core for a.) HEU EOC, b.)HEU EOC DSA and c.) The percentage differences between the HEU EOC and the HEU EOC DSA ........15 Figure 12. Radial power distribution for the upper half of the core for a.) LEU SU, b.)LEU SU DSA and c.) The percentage differences between the LEU SU and the LEU SU DSA..... 16

Figure 13. Radial power distribution for the lower half of the core for a.) LEU SU, b.)LEU SU DSA and c.) The percentage differences between the LEU SU and the LEU SU DSA...

Figure 14. Radial power distribution for the upper half of the core for a.) LEU EOC, b.)LEU EOC DSA and c.) The percentage differences between the LEU EOC and the LEU EOC DSA.........18 Figure 15. Radial power distribution for the lower half of the core for a.) LEU EOC, b.)LEU EOC DSA and c.) The percentage differences between the LEU EOC and the LEU EOC DSA.........19

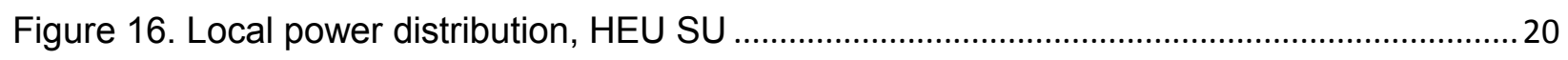

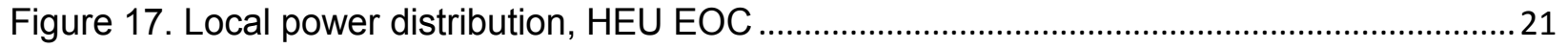

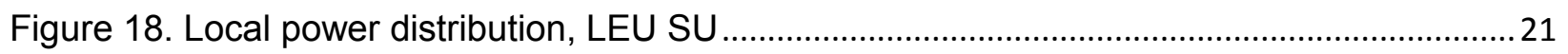

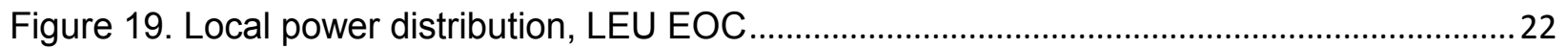

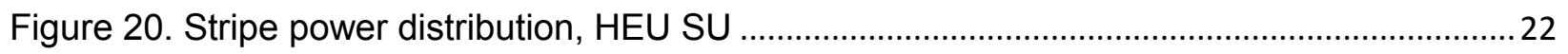

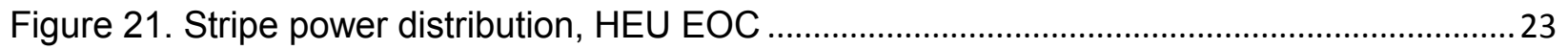

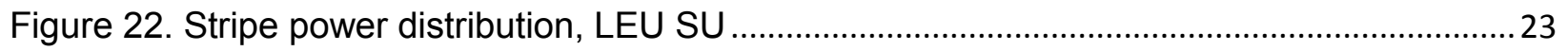

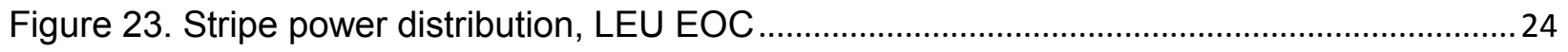




\section{List of Tables}

Table 1. Descriptors for the calculations …........................................................ 7

Table 2. Effect of shim arm depletion on the worth of the shim arms.......................... 8

Table 3. Values and positions for the hottest points, stripes and half fuel elements. NA indicates no calculations with the C7SDA Cd distributions were made for the HEU fuel. The fuel element locations are shown in Figure 3 with $L$ representing the lower half of the fuel element and $U$ the upper half of the fuel element. 25 Table 4. Per cent change in highest point-wise power when comparing fresh and 25 cycle depleted shim arms. 25 Table 5. Calculation of the kinetics parameters for the different fuels, core states and shim arm conditions. 


\section{Introduction}

The research reactor at the National Institute of Standards and Technology (NBSR) is a high burnup research reactor with a cycle length of 38.5 days. Presently the NBSR is fueled with high-enriched uranium (HEU) fuel, but conversion to low-enriched uranium (LEU) fuel is being considered. The two fuels have different forms. The HEU fuel is $93 \%$ enriched $\mathrm{U}_{3} \mathrm{O}_{8}$ mixed with aluminum to a density of $3.612 \mathrm{~g} / \mathrm{cm}^{3}$. The LEU fuel is presently assumed to be a foil of $19.75 \%$ enriched uranium alloyed with molybdenum to $10 \mathrm{wt} \%$ Mo. It is referred to as U10Mo and has a density of $17.2 \mathrm{~g} / \mathrm{cm}^{3}$.

When the NBSR is fueled with the HEU fuel, at the startup (SU) of a new cycle, the core has approximately $7.4 \mathrm{~kg}$ of ${ }^{235} \mathrm{U}$ distributed over 30 fuel elements. The loading ranges from a low of approximately 125 grams of ${ }^{235} \mathrm{U}$ in an irradiated fuel element in its final cycle to $350 \mathrm{~g}$ of ${ }^{235} \mathrm{U}$ of for a fresh, unirradiated fuel element. During one cycle an average of $31.7 \mathrm{~g}$ of ${ }^{235} \mathrm{U}$ is burned per fuel element, equivalent to $951 \mathrm{~g}$ for the entire core. At the end-of-cycle (EOC) the loadings range from $94 \mathrm{~g}$ to $322 \mathrm{~g}{ }^{235} \mathrm{U}$. At the end of each cycle, four fuel elements are removed from the core. The remaining 26 fuel elements are moved to new locations, and four fresh fuel elements are inserted. With this fuel management, 14 fuel elements are in the reactor for seven cycles and 16 fuel elements are in the reactor for eight cycles. The down-time between cycles for moving the fuel elements is on the order of 10.5 days; therefore at $\mathrm{SU}{ }^{135} \mathrm{Xe}$, a significant fission product poison, is no longer present in the fuel. The LEU fuel has been designed so that the NBSR can maintain the present fuel management scheme.

The main reactivity control of the NBSR is four shim arms consisting of hollow, helium filled, quasi-rectangular cadmium boxes clad on the inside and outside with aluminum. These boxes are manufactured by pressing a $9-\mathrm{cm}$ diameter concentric Al-Cd-Al hollow cylinder until it is almost flat. The final shim arm dimensions are $2.54 \mathrm{~cm}$ (1 in) wide, $12.7 \mathrm{~cm}$ (5 in) high and $132 \mathrm{~cm}$ (52 in) in length with the cadmium being $0.1 \mathrm{~cm}(0.04 \mathrm{in})$ thick. The shim arms in the NBSR are mounted in a semaphore configuration in that they slice through the core in four different vertical planes. Figure 1 is an elevation view of the reactor neutronic model highlighting Shim Arm \#2 in the nominal startup position, i.e. $21.7^{\circ}$ withdrawn. Full insertion of the shim arms is defined as $0^{\circ}$ and full withdrawal is when they are horizontal, which is $41^{\circ}$ from fully inserted. In Figure 1 Shim Arm \#2 pivots from the right hand side. The fueled region is within the box and designated with "core boundary" on the figure. 


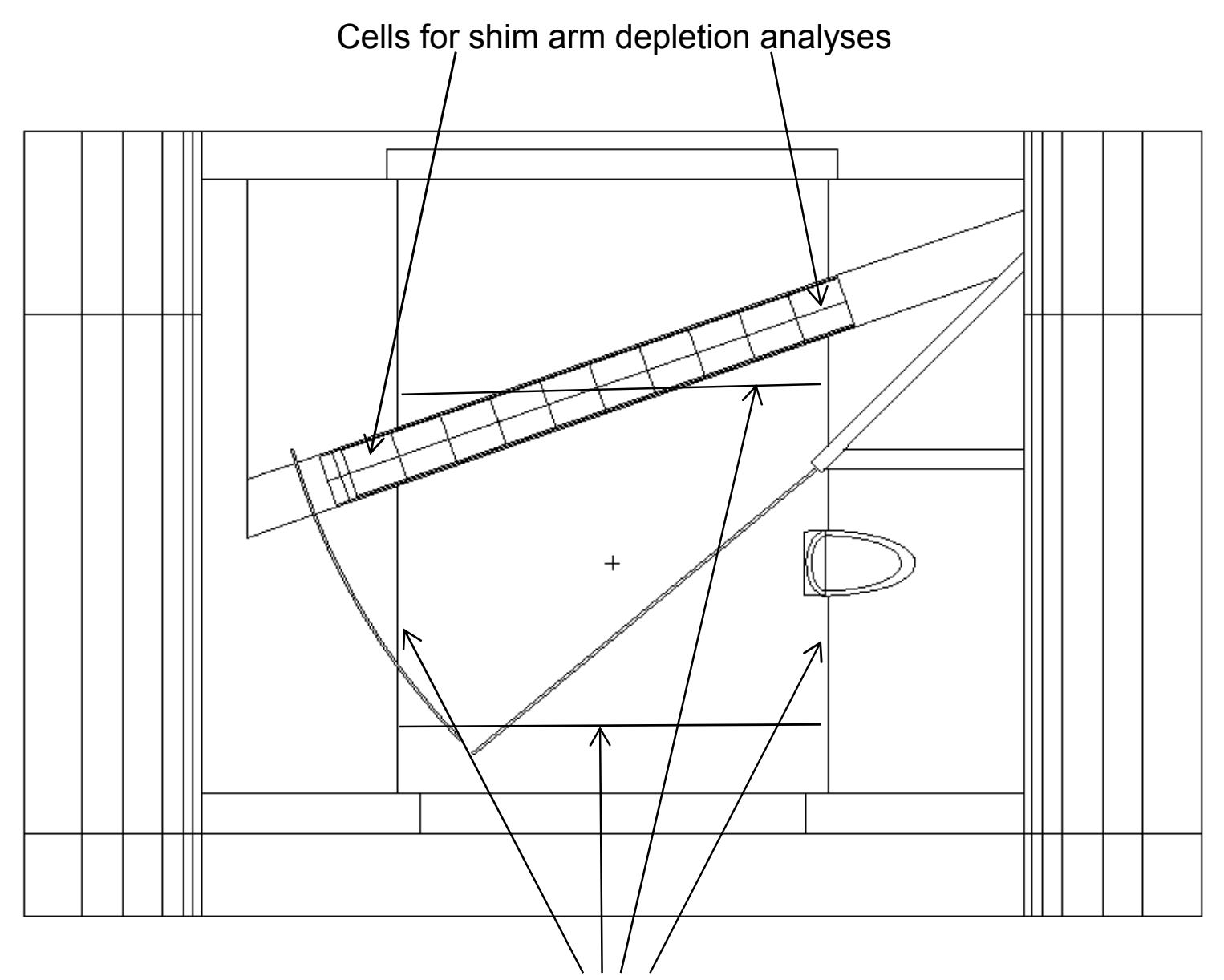

Active Core Boundaries

Figure 1. Vertical cross section of the NBSR at the location of the \#2 Shim Arm.

Figure 2 is a view of the reactor at the mid-plane plotted from the neutronic model. The 30 squares represent the unfueled gap regions of each fuel element and the circles represent thimbles that pass through the core for experiment irradiation, instrumentation, and fine reactivity control. Figure 3 shows the fuel element designation for the NBSR. There are 13 columns labeled $A$ through $M$ and 7 rows labeled 1-7. The areas denoted as "<>" are the 3.5 in in-core irradiation thimbles and $\langle R R>$ is the location of the regulating rod. In Figure 2, the hexagonal grid represents computational cell boundaries and does not represent any physical structures. There are four sets of horizontal lines that define where the shim arms travel. These lines are also computational cell boundaries. Each set of horizontal lines is labeled with its respective shim arm number. The "U" shaped structures in the shim arm channels represent slices through each of the shim arm catchers, which are located below the shim arms as seen in Figure 1. These catchers were included as a safety measure in the event of a shim 
arm breaking. Outside the core region are four more "U" shaped features, which represent the locations of the ends of the shim arms at SU.

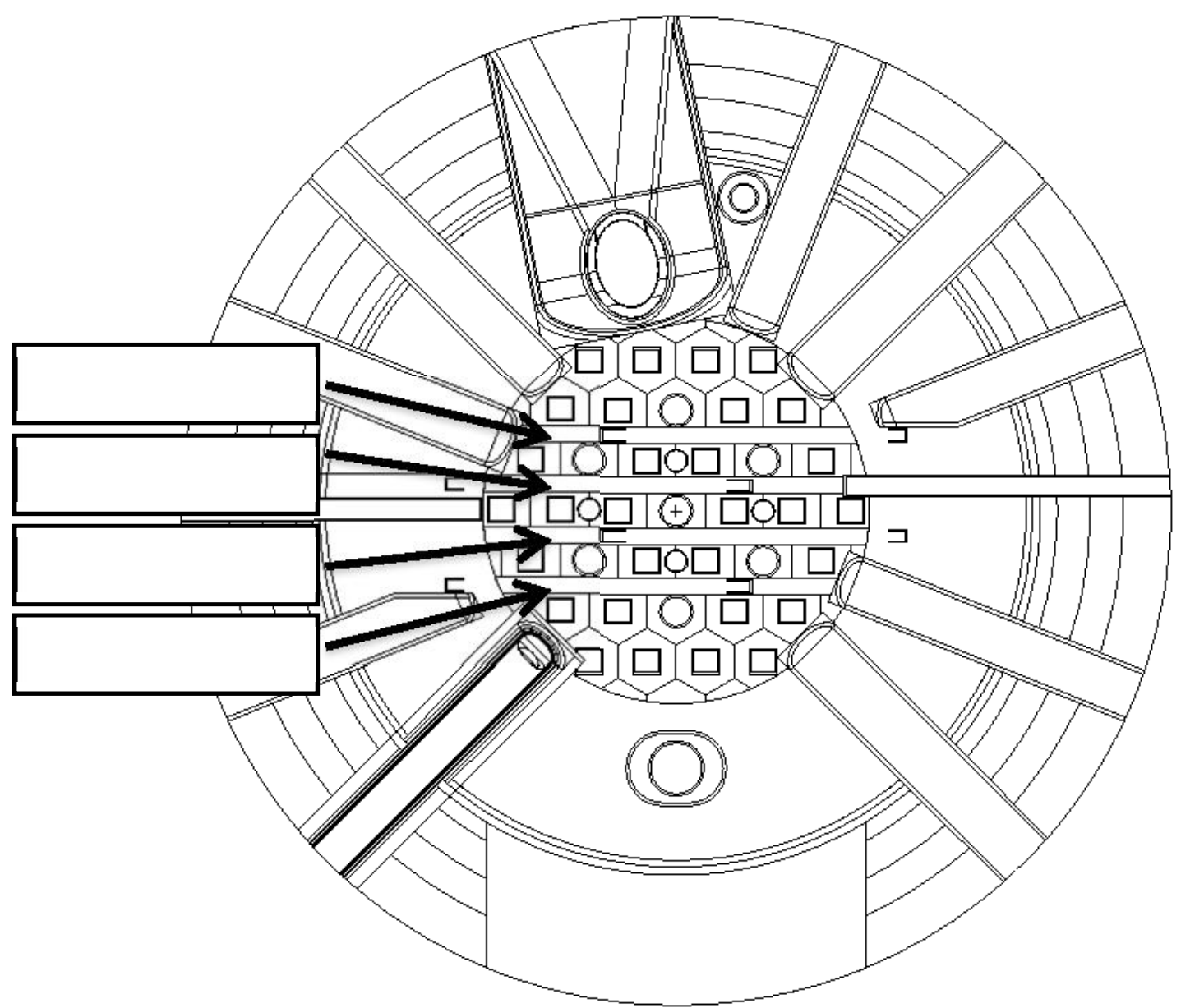

Figure 2. Horizontal cross section of the NBSR at the mid-plane of the reactor.

\begin{tabular}{|l|c|c|c|c|c|c|c|c|c|c|c|c|}
\hline & & \multicolumn{3}{|c|}{ COLD SOURCE } & & & & & & & \\
\hline & & & D1 & & F1 & & H1 & & J1 & & & \\
\hline & & C2 & & E2 & & $<>$ & & I2 & & K2 & & \\
\hline & B3 & & $<>$ & & F3 & & H3 & & $<>$ & & L3 & \\
\hline A4 & & C4 & & E4 & & $<>$ & & I4 & & K4 & & M4 \\
\hline & B5 & & $<>$ & & F5 & & H5 & & $<>$ & & L5 & \\
\hline & & C6 & & E6 & & $<$ RR & & I6 & & K6 & & \\
\hline & & & D7 & & F7 & & H7 & & J7 & & & \\
\hline
\end{tabular}

Figure 3. Element Position Designation 
The shim arms are effective as control mechanisms since the cadmium has an extremely large thermal neutron capture cross section dominated by the isotope ${ }^{113} \mathrm{Cd}$ $\left(\sigma_{\text {th }}=\sim 20600 \mathrm{~b}\right.$ [1]), which makes up $12.22 \%$ [2] of natural cadmium. This large capture cross section means that over time the ${ }^{113} \mathrm{Cd}$ is transmuted, or "burned out", to ${ }^{114} \mathrm{Cd}$ and the shim arms become depleted of that isotope. This depletion is observable through changes in the shim arm critical angle for the SU; in subsequent cycles the critical angle for the shim arms at SU becomes more inserted.

Technical Specification (TS) 3.3 [3] states that that if the reactor cannot be maintained subcritical with the highest worth shim arm withdrawn, then the set of shim arms must be replaced. It is standard procedure to replace the shim arms after 25 cycles. Operating experience has demonstrated that 25 cycles is sufficient to meet the requirements of TS 3.3 .

Figure 1 illustrates that only portions of the shim arms are in the fueled core region during operation. During a cycle the shim arms are gradually withdrawn to the horizontal position. When the shim arms are withdrawn to $30^{\circ}$ there are no sections of the shim arms still in the fueled region. The shim arms will deplete more rapidly in regions with higher thermal flux. Because the location of the thermal flux peak is in the radial center of the core, the shim arms tend to deplete more rapidly in the center of the arm than near the pivot.

\section{Methodology}

Two previous studies examined the changes in the ${ }^{113} \mathrm{Cd}$ distributions as a function of time $[4,5]$. The objective of the work reported here is to apply the results from the previous studies to determine if there will be any anticipated effects on the safety of the NBSR after shim arm depletion when the NBSR is loaded with LEU fuel. Additionally the work will help determine if the present shim arm replacement scheme for HEU fuel is appropriate for LEU fuel.

One of the previous studies was to determine the ${ }^{113} \mathrm{Cd}$ distribution per cycle in the shim arms when the NBSR if fueled with the present HEU fuel [4] for a total of 30 cycles. The other study was to determine the ${ }^{113} \mathrm{Cd}$ distribution, per cycle for a total of 30 cycles, for the proposed U10Mo LEU fuel in the COMP7 configuration, which featured a shorter fuel element design [4]. The methodology used for both analyses was identical, the only differences being the makeup of the fuel (HEU vs. LEU) and the geometry; with each HEU fuel element having two $11 \mathrm{in} .(27.94 \mathrm{~cm})$ fueled regions separated with a 7 in. $(17.78 \mathrm{~cm})$ gap versus each LEU fuel element having two 7 in. $(17.78 \mathrm{~cm})$ long fueled regions separated with a 7 in. $(17.78 \mathrm{~cm})$ gap in the COMP7 configuration. 
MCNP [6] is the neutronics analysis tool of choice for the NBSR. MCNP has been previously used to design and analyze the new cold neutron source and to perform neutronics calculations needed for relicensing and safety analysis [7]. In performing the analyses of the changes to the ${ }^{113} \mathrm{Cd}$ distribution as a function of depletion $[4,5]$, the MCNP model of the NBSR was modified by dividing each shim arm into 20 mesh cells, as shown in Figure 1.

The HEU and LEU fuel element inventories used for the two previous reports [3, 4] were determined with the MONTEBURNS [8] code, which iteratively uses the MCNP and ORIGEN2 [9] codes. The details of the analysis were reported previously [10]. For that analysis, five different inventories were developed: a beginning-of-cycle equilibrium core (BOC); an equilibrium core one quarter through the cycle (1/4); a middle-of-cycle equilibrium core (MID); an equilibrium core three quarters through the cycle (3/4); and an end-of-cycle equilibrium core (EOC). BOC was chosen over a startup core (without short-lived fission products) since in the first day of operation after a new startup, the shim arms move approximately $4.5^{\circ}$ as the high absorption, short lived fission products, such as ${ }^{135} \mathrm{Xe}$, build up in the core. After that, during the next nine days the shim arms travel $3.1^{\circ}$. As the shim arms are removed from the reactor the rate of withdrawal is decreased.

Several assumptions were made for the generation of those inventories. The material in each half fuel element was homogenized, so there was no accounting for uneven burnup along the axial dimension or between fuel plates. Because of limitations in MONTEBURNS there are a maximum number of 59 different materials that can be determined, so east-west symmetry was invoked with the result being a limit of the number of fuel compositions being 30. The analyses reported in [10] show that there is some asymmetry in the power distributions, especially around the cold neutron source (CNS). Other assumptions involved with the generation of inventories were discussed in those reports.

More recently fuel inventories for both the HEU and LEU fuels have been recalculated [9] using the MCNPX2.6.0 [12] code with the BURN module along with the ENDF/BVII.0 libraries. However, for the analyses of the effects of cadmium depletion presented here, the ${ }^{113} \mathrm{Cd}$ distributions in the shim arms that were calculated as a function of cycle were determined using inventories generated with MONTEBURNS [4, 5].

As is shown in Figure 1, each shim arm was divided into 20 separate cells with a volume of $19.68 \mathrm{~cm}^{3}$, and the cadmium in the fresh, unirradiated shim arms is evenly distributed in each cell. For the ${ }^{113} \mathrm{Cd}$ depletion calculations, MCNP was run and the interaction rate for the ${ }^{113} \mathrm{Cd}$ was tallied in each of the 80 cells for five different times in the cycle, the BOC, $1 / 4, \mathrm{MID}, 3 / 4$, and EOC. The interaction rate of the ${ }^{113} \mathrm{Cd}$ was 
determined for each step in the cycle and the amount of ${ }^{113} \mathrm{Cd}$ consumed in each cell was the integral of interaction rate over time. The amount of ${ }^{113} \mathrm{Cd}$ consumed in each cell was then subtracted from the amount in each cell at the start of that cycle. This process was repeated for 30 cycles. Hence, there were numerous assumptions invoked by this methodology which were necessary to keep the effort spent on the analysis within reason:

1. The ${ }^{113} \mathrm{Cd}$ interaction rate over a cycle assumes the five calculated reaction rates are constant over the interval for which they were determined based on the MCNP-calculated reaction rate.

2. The ${ }^{113} \mathrm{Cd}$ concentration stays constant during a cycle, and is only changed at the end of a cycle. However the reaction rates are allowed to change during each time step mentioned above over the cycle as the shim arms are withdrawn from the core.

3. There is no significant change in the concentration of the other cadmium isotopes other than ${ }^{114} \mathrm{Cd}$ (due to the ${ }^{113} \mathrm{Cd}(\mathrm{n}, \gamma){ }^{114} \mathrm{Cd}$ reaction).

4. The fuel element inventories were determined with fresh, unirradiated shim arms, no potential shifts in the inventories due to depletion of the shim arms were considered.

5. The depletion is analyzed discretely in 20 regions of each shim arm.

To determine the depletion over an entire cycle, a numerical integration was performed over the cycle from the data for each of the five core states. This numerical integration was performed on each of the 80 different shim arm cells to determine the amount of ${ }^{113} \mathrm{Cd}$ transmuted during that cycle. The amount of ${ }^{113} \mathrm{Cd}$ transmuted during a cycle was subtracted from the amount that was in each cell at the beginning of the cycle and added to the amount of ${ }^{114} \mathrm{Cd}$ that was in each cell at the beginning of the cycle. This determined the set of cadmium inventories that were included for the calculations during the following cycle. Thus, a full solution of the Bateman equations was not performed and a first-order approximation was obtained based on an average interaction rate per cycle.

\section{Shim Arm Worth}

The HEU core states were calculated with fresh shim arms and shim arms with the cadmium depletion distribution for the HEU core. The core states for the LEU fuel were also calculated assuming a fresh set of shim arms and cadmium depletion distributions that were determined for the HEU and the COMP7 cores. The descriptors used throughout this report for the different calculations are defined in Table 1. 
Table 1. Descriptors for the calculations

\begin{tabular}{|c|c|c|c|}
\hline Descriptor & Fuel & State & Cadmium Depletion \\
\hline HEU SU & HEU & SU & Uniform, no depletion \\
\hline HEU EOC & HEU & EOC & Uniform, no depletion \\
\hline HEU SU DSA ${ }^{a}$ & HEU & SU & HEU DSA Distribution after 25 cycles \\
\hline HEU EOC DSA & HEU & EOC & HEU DSA Distribution after 25 cycles \\
\hline LEU SU & LEU & SU & Uniform, no depletion \\
\hline LEU EOC & LEU & EOC & Uniform, no depletion \\
\hline LEU SU DSA & LEU & SU & HEU DSA Distribution after 25 cycles \\
\hline LEU EOC DSA & LEU & EOC & HEU DSA Distribution after 25 cycles \\
\hline LEU SU C7DSA & LEU & SU & COMP7 DSA Distribution after 25 cycles \\
\hline LEU EOC C7DSA & LEU & EOC & COMP7 DSA Distribution after 25 cycles \\
\hline \multicolumn{4}{|c|}{${ }^{\mathrm{a}} \mathrm{DSA}=$ depleted shim arms } \\
\hline
\end{tabular}

The effect on the shim arm depletion on the total shim arm worth was investigated for different fuels, core states and shim arm depletions and is shown in Table 2. The second column is the integral worth calculated from the $k_{\text {eff }}$ when the shim arms are fully inserted and when they are fully withdrawn. The shim arm worth is then in units of $\% \Delta \mathrm{k} / \mathrm{k}$ :

$$
\text { Integral Worth }=\% \Delta k / k=100^{*}\left(1 / k_{\text {eff, inserted }}-1 / k_{\text {eff, withdrawn }}\right)
$$

The third column is the integral worth assuming the shim arms depleted with either the depleted shim arm (DSA) or the COMP7 depleted shim arm (C7DSA) cadmium distributions in the shim arms. The fourth column is the percent change of the integral shim arm worth from the fresh shim arms to the shim arms after 25 cycles. 
Table 2. Effect of shim arm depletion on the worth of the shim arms.

\begin{tabular}{|l|c|c|c|}
\hline & \multicolumn{2}{|c|}{ Worth, \% $\mathbf{\Delta k} / \mathbf{k}$} & \\
\hline & Fresh & Depleted & $\%$ Change \\
\hline HEU SU DSA & 24.9 & 19.6 & $-21.3 \%$ \\
\hline LEU SU DSA & 24.0 & 18.7 & $-22.1 \%$ \\
\hline LEU SU C7DSA & 24.0 & 18.4 & $-23.3 \%$ \\
\hline HEU EOC DSA & 27.2 & 21.4 & $-21.5 \%$ \\
\hline LEU EOC DSA & 25.9 & 20.2 & $-21.8 \%$ \\
\hline LEU EOC C7DSA & 25.9 & 19.8 & $-22.4 \%$ \\
\hline
\end{tabular}

\section{Shutdown Margin}

NBSR Technical Specification 3.1.2, Reactivity Limitations, states that the core cannot be loaded such that the excess reactivity will exceed $15 \% \Delta \mathrm{k} / \mathrm{k}$ and the NBSR shall not be operated if it cannot be kept shutdown with the most reactive shim arm fully retracted. To determine if these conditions are met, $k_{\text {eff }}$ was calculated under the following conditions: all shim arms inserted (shutdown reactivity), all shim arms withdrawn (excess reactivity), and three of the four shim arms inserted with the other withdrawn (shutdown margin). The calculations were performed with the SU inventory where the excess reactivity is greatest.

The results are presented in Figures 4-7, which show the value of $k_{\text {eff }}$ as a function of cycle when each shim arm is withdrawn while the other three are inserted. These figures demonstrate that even though the value of $k_{\text {eff }}$ starts to increase after 15 cycles, the shim arms continue to provide adequate shutdown margin for the LEU core for 25 cycles, when they are scheduled for replacement with the present shim arm replacement scheme. Hence, it is expected that the present shim arm replacement scheme should be adequate for the LEU fuel. 


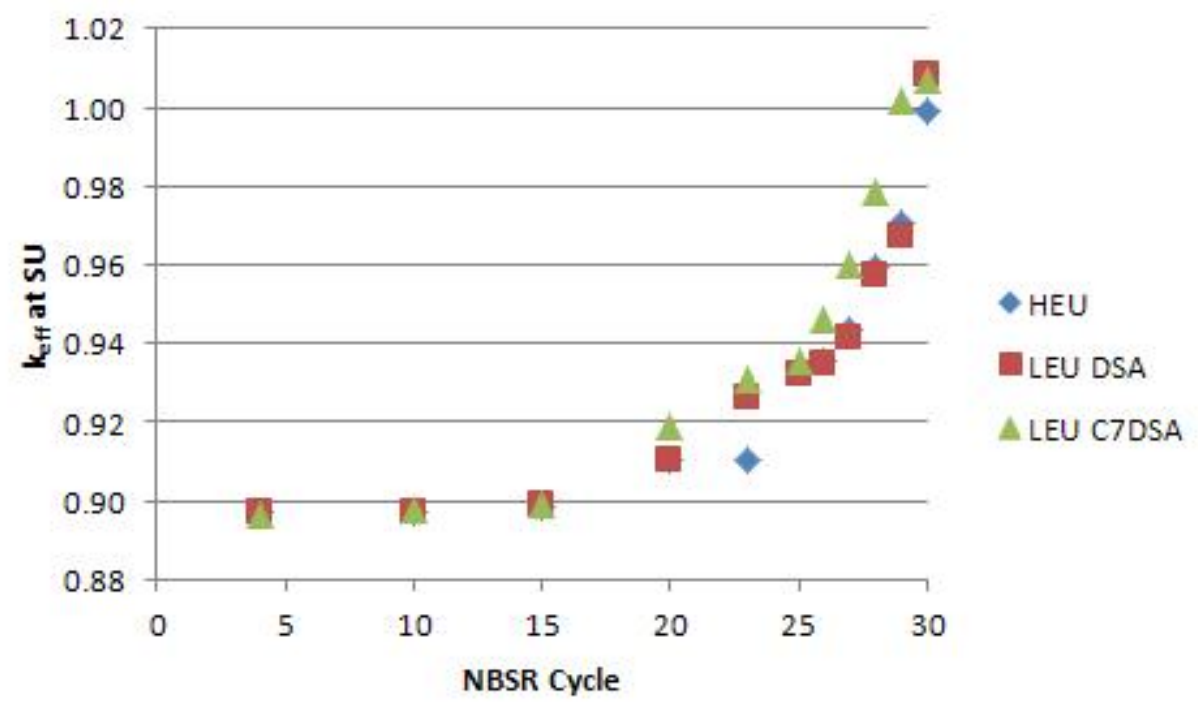

Figure 4. Shutdown margin 1: The value of $K_{\text {eff }}$ at $S U$ for the HEU and LEU cores with the DSA (HEU and LEU) and C7DSA distributions when Shim Arm \#1 is withdrawn and the other three are inserted.

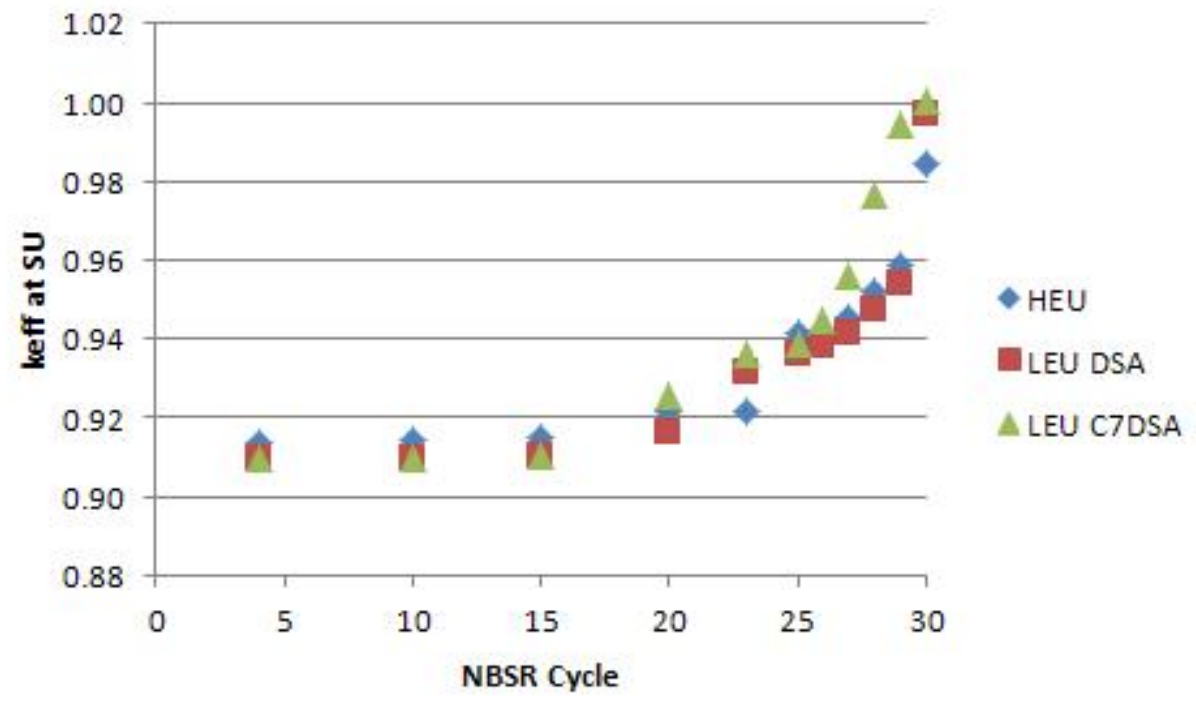

Figure 5. Shutdown margin 2: The value of $\mathrm{K}_{\text {eff }}$ at $\mathrm{SU}$ for the HEU and LEU cores with the DSA (HEU and LEU) and C7DSA distributions when Shim Arm \#2 is withdrawn and the other three are inserted. 


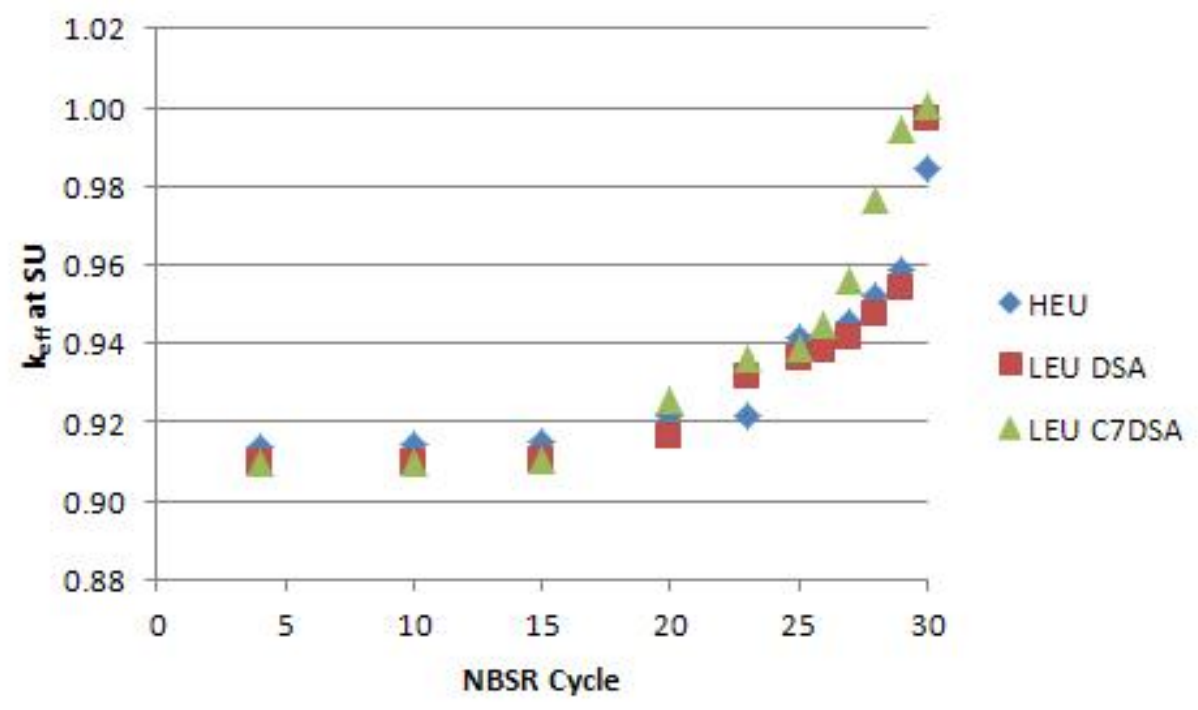

Figure 6. Shutdown margin 3: The value of $\mathrm{K}_{\text {eff }}$ at $S U$ for the HEU and LEU cores with the DSA (HEU and LEU) and C7DSA distributions when Shim Arm \#3 is withdrawn and the other three are inserted.

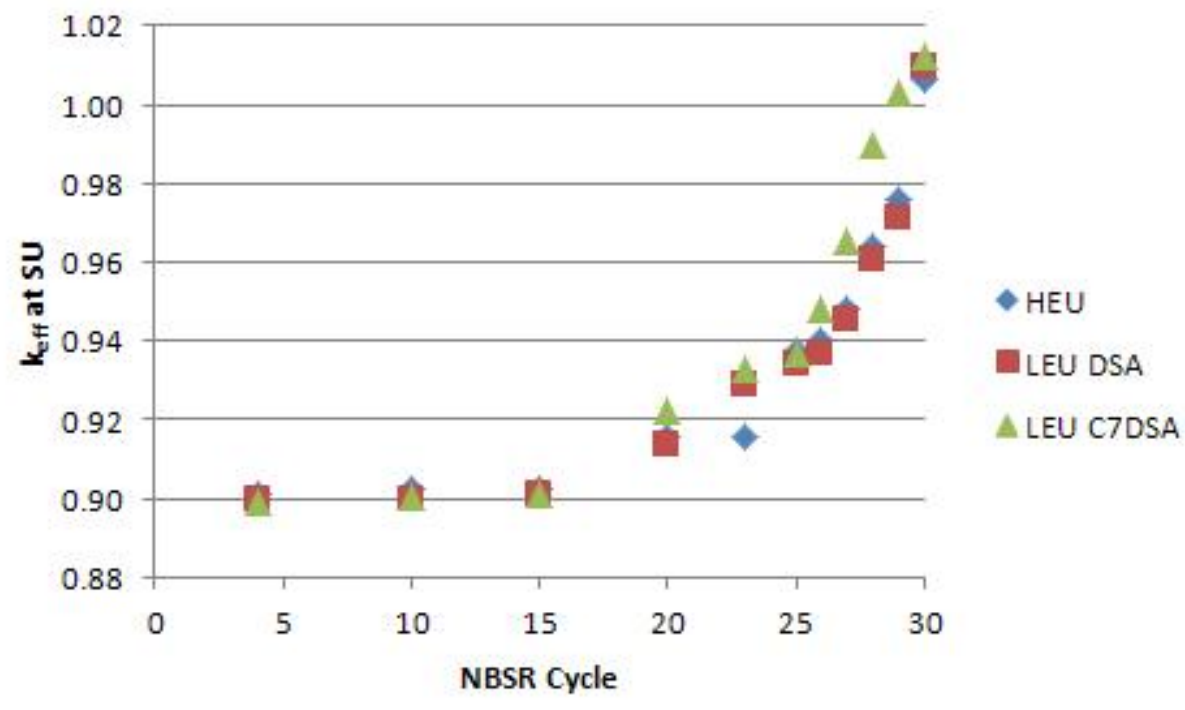

Figure 7. Shutdown margin 4: The value of $K_{\text {eff }}$ at $S U$ for the HEU and LEU cores with the DSA (HEU and LEU) and C7DSA distributions when Shim Arm \#4 is withdrawn and the other three are inserted. 


\section{Radial Power Distributions}

Radial power distributions were calculated for the HEU and the LEU fuels in the SU and EOC states. The radial power distributions are the relative power in each half fuel element such that unity represents $20 / 60 \mathrm{MW}$ because the reactor power is $20 \mathrm{MW}$ and there are 60 half fuel elements. The radial power distributions are helpful for determining the total heat generated in each half fuel element and hence, they are used to determine if there will be a need to adjust the cooling between the inner and outer plena of the cooling system.

Figures 8-15 show the radial power distributions for each core state with the different shim arm depletions along with comparisons between the distributions when the shim arms are fresh and depleted (DSA state). These figures demonstrate that as the shim arms deplete the power shifts slightly from the lower half of the core to the upper half of the core and there are only small changes in the radial power distribution. The results of the radial power distribution calculations using the C7DSA cadmium distribution were similar to the results when using the DSA cadmium distribution. For EOC, $85 \%$ of the 60 half fuel elements showed power levels that were within $1 \%$ of each other and the other $15 \%$ were between 1 and $2 \%$ of each other. At SU, $80 \%$ of the half fuel elements had powers within $1 \%$ of each other and only two half fuel elements had power differences between 2 and $3 \%$. These differences are not large enough to be a concern for the power peaking calculations. 


\begin{tabular}{|c|c|c|c|c|c|c|c|c|c|c|c|c|c|}
\hline \multicolumn{14}{|c|}{ HEU SU } \\
\hline \multicolumn{14}{|c|}{ Upper Core } \\
\hline & A & B & $\mathbf{C}$ & D & $\bar{E}$ & $\mathbf{F}$ & $\mathbf{G}$ & $\mathbf{H}$ & I & $\mathbf{J}$ & $\mathbf{K}$ & $\mathbf{L}$ & $M$ \\
\hline & & & & \multicolumn{3}{|c|}{ COLD SOURCE } & & & & & & & \\
\hline 1 & & & & 0.98 & & 1.05 & & 1.11 & & 0.99 & & & \\
\hline 2 & & & 0.95 & & 1.02 & & $<>$ & & 0.95 & & 0.82 & & \\
\hline 3 & & 0.74 & & $<>$ & & 0.91 & & 0.90 & & $<>$ & & 0.72 & \\
\hline 4 & 0.64 & & 0.71 & & 0.82 & & $<>$ & & 0.81 & & 0.70 & & 0.64 \\
\hline 5 & & 0.66 & & $<>$ & & 0.74 & & 0.74 & & $<>$ & & 0.68 & \\
\hline 6 & & & 0.72 & & 0.80 & & $<\mathrm{RR}>$ & & 0.86 & & 0.85 & & \\
\hline 7 & & & & 0.91 & & 0.91 & & 0.92 & & 0.97 & & & \\
\hline
\end{tabular}

Figure 8a.

\begin{tabular}{|c|c|c|c|c|c|c|c|c|c|c|c|c|c|}
\hline \multicolumn{14}{|c|}{ HEU SU DSA } \\
\hline \multicolumn{14}{|c|}{ Upper Core } \\
\hline & $\mathbf{A}$ & B & C & D & $E$ & $\mathbf{F}$ & $\mathbf{G}$ & $\mathrm{H}$ & I & $\mathbf{J}$ & $\mathbf{K}$ & $\mathbf{L}$ & $\mathbf{M}$ \\
\hline & & & & \multicolumn{3}{|c|}{ COLD SOURCE } & & & & & & & \\
\hline 1 & & & & 0.98 & & 1.07 & & 1.12 & & 1.01 & & & \\
\hline 2 & & & 0.95 & & 1.02 & & $<>$ & & 0.95 & & 0.85 & & \\
\hline 3 & & 0.77 & & $<>$ & & 0.92 & & 0.90 & & $<>$ & & 0.75 & \\
\hline 4 & 0.69 & & 0.73 & & 0.82 & & $<>$ & & 0.83 & & 0.72 & & 0.69 \\
\hline 5 & & 0.69 & & $<>$ & & 0.75 & & 0.74 & & $<>$ & & 0.70 & \\
\hline 6 & & & 0.75 & & 0.81 & & $<\mathrm{RR}>$ & & 0.87 & & 0.87 & & \\
\hline 7 & & & & 0.93 & & 0.92 & & 0.92 & & 0.98 & & & \\
\hline
\end{tabular}

Figure 8b.

\begin{tabular}{|c|c|c|c|c|c|c|c|c|c|c|c|c|c|}
\hline \multicolumn{14}{|c|}{ Percent change from HEU SU to HEU SU DSA } \\
\hline \multicolumn{3}{|c|}{ Upper Core } & \multirow[b]{2}{*}{$\mathbf{C}$} & \multirow[b]{2}{*}{$\mathbf{D}$} & \multirow[b]{2}{*}{$E$} & \multirow[b]{2}{*}{$\mathbf{F}$} & \multirow[b]{2}{*}{ G } & \multirow[b]{2}{*}{$\mathbf{H}$} & \multirow[b]{2}{*}{$\mathbf{I}$} & \multirow[b]{2}{*}{$\mathbf{J}$} & \multirow[b]{2}{*}{$\mathbf{K}$} & \multirow[b]{2}{*}{$\mathbf{L}$} & \multirow[b]{2}{*}{$\mathbf{M}$} \\
\hline & A & $\mathbf{B}$ & & & & & & & & & & & \\
\hline & & & & COLD & JRCE & & & & & & & & \\
\hline 1 & & & & 0.0 & & 1.8 & & 1.0 & & 2.1 & & & \\
\hline 2 & & & -0.2 & & -0.2 & & $<>$ & & 0.4 & & 2.9 & & \\
\hline 3 & & 3.5 & & $<>$ & & 1.1 & & 0.4 & & $<>$ & & 5.0 & \\
\hline 4 & 6.9 & & 2.6 & & 0.4 & & $<>$ & & 1.9 & & 2.8 & & 8.8 \\
\hline 5 & & 5.7 & & $<>$ & & 1.0 & & 0.4 & & $<>$ & & 3.3 & \\
\hline 6 & & & 4.7 & & 1.5 & & $<\mathrm{RR}>$ & & 1.4 & & 1.5 & & \\
\hline 7 & & & & 2.3 & & 1.1 & & 0.7 & & 1.6 & & & \\
\hline
\end{tabular}

Figure 8c.

Figure 8. Radial power distribution for the upper half of the core for a.) HEU SU, b.)HEU SU DSA and c.) The percentage differences between the HEU SU and the HEU SU DSA 


\begin{tabular}{|c|c|c|c|c|c|c|c|c|c|c|c|c|c|}
\hline \multicolumn{14}{|c|}{ HEU SU } \\
\hline \multicolumn{14}{|c|}{ Lower core } \\
\hline & A & B & $\mathbf{C}$ & D & $\bar{E}$ & $\mathbf{F}$ & $\mathbf{G}$ & $\mathbf{H}$ & I & $\mathrm{J}$ & $\mathbf{K}$ & $\mathbf{L}$ & $M$ \\
\hline & & & & \multicolumn{3}{|c|}{ COLD SOURCE } & & & & & & & \\
\hline 1 & & & & 1.07 & & 1.17 & & 1.23 & & 1.14 & & & \\
\hline 2 & & & 1.24 & & 1.27 & & $<>$ & & 1.28 & & 1.26 & & \\
\hline 3 & & 1.25 & & $<>$ & & 1.27 & & 1.27 & & $<>$ & & 1.24 & \\
\hline 4 & 1.24 & & 1.19 & & 1.22 & & $<>$ & & 1.21 & & 1.15 & & 1.20 \\
\hline 5 & & 1.20 & & $<>$ & & 1.05 & & 1.04 & & $<>$ & & 1.15 & \\
\hline 6 & & & 1.12 & & 1.09 & & $<\mathrm{RR}>$ & & 1.08 & & 1.10 & & \\
\hline 7 & & & & 1.04 & & 0.99 & & 0.99 & & 1.03 & & & \\
\hline
\end{tabular}

Figure 9a.

\begin{tabular}{|c|c|c|c|c|c|c|c|c|c|c|c|c|c|}
\hline \multicolumn{14}{|c|}{ HEU SU DSA } \\
\hline \multicolumn{14}{|c|}{ Lower core } \\
\hline & A & B & C & D & $E$ & $\mathbf{F}$ & $\mathbf{G}$ & $\mathrm{H}$ & I & $\mathbf{J}$ & $\mathbf{K}$ & $\mathbf{L}$ & $\mathbf{M}$ \\
\hline & & & & \multicolumn{3}{|c|}{ COLD SOURCE } & & & & & & & \\
\hline 1 & & & & 1.04 & & 1.14 & & 1.21 & & 1.12 & & & \\
\hline 2 & & & 1.22 & & 1.26 & & $<>$ & & 1.26 & & 1.25 & & \\
\hline 3 & & 1.22 & & $<>$ & & 1.25 & & 1.26 & & $<>$ & & 1.21 & \\
\hline 4 & 1.22 & & 1.19 & & 1.20 & & $<>$ & & 1.20 & & 1.15 & & 1.18 \\
\hline 5 & & 1.18 & & $<>$ & & 1.04 & & 1.03 & & $<>$ & & 1.12 & \\
\hline 6 & & & 1.11 & & 1.07 & & $<R R>$ & & 1.06 & & 1.08 & & \\
\hline 7 & & & & 1.03 & & 0.99 & & 0.98 & & 1.02 & & & \\
\hline
\end{tabular}

Figure 9b.

\begin{tabular}{|c|c|c|c|c|c|c|c|c|c|c|c|c|c|}
\hline \multicolumn{14}{|c|}{ Percent change from HEU SU to HEU SU DSA } \\
\hline \multicolumn{14}{|c|}{ Lower core } \\
\hline & A & $\mathbf{B}$ & $\mathbf{C}$ & $\mathbf{D}$ & $\bar{E}$ & $\mathbf{F}$ & $\mathbf{G}$ & $\mathbf{H}$ & $\mathbf{I}$ & $\mathbf{J}$ & $\mathbf{K}$ & $\mathbf{L}$ & $\mathbf{M}$ \\
\hline & & & & \multicolumn{10}{|c|}{ COLD SOURCE } \\
\hline 1 & & & & -2.1 & & -2.4 & & -1.6 & & -1.3 & & & \\
\hline 2 & & & -1.8 & & -1.0 & & $<>$ & & $\begin{array}{l}-1.3 \\
\end{array}$ & & -1.1 & & \\
\hline 3 & & -2.3 & & $<>$ & & -1.8 & & -1.2 & & $<>$ & & -2.0 & \\
\hline 4 & -1.8 & & -0.3 & & -2.4 & & $<>$ & & -1.1 & & -0.6 & & -1.9 \\
\hline 5 & & -1.5 & & $<>$ & & -1.1 & & -1.2 & & $<>$ & & -2.6 & \\
\hline 6 & & & -0.9 & & -1.0 & & $<\mathrm{RR}>$ & & -1.4 & & -1.4 & & \\
\hline 7 & & & & -0.5 & & -0.3 & & -1.3 & & -1.2 & & & \\
\hline
\end{tabular}

Figure 9c.

Figure 9. Radial power distribution for the lower half of the core for a.) HEU SU, b.)HEU SU DSA and c.) The percentage differences between the HEU SU and the HEU SU DSA 


\begin{tabular}{|c|c|c|c|c|c|c|c|c|c|c|c|c|c|}
\hline \multicolumn{14}{|c|}{ HEU EOC } \\
\hline \multicolumn{14}{|c|}{ Upper Core } \\
\hline & $\mathbf{A}$ & B & C & $\mathbf{D}$ & $\bar{E}$ & $\mathbf{F}$ & $\mathbf{G}$ & $\mathbf{H}$ & $T$ & $\mathrm{~J}$ & $\mathbf{K}$ & $\mathbf{L}$ & $\mathbf{M}$ \\
\hline & & & & \multicolumn{3}{|c|}{ COLD SOURCE } & & & & & & & \\
\hline 1 & & & & 1.00 & & 1.11 & & 1.18 & & 1.11 & & & \\
\hline 2 & & & 1.08 & & 1.11 & & $<>$ & & 1.14 & & 1.16 & & \\
\hline 3 & & 1.09 & & $<>$ & & 1.07 & & 1.07 & & $<>$ & & 1.16 & \\
\hline 4 & 1.10 & & 1.03 & & 1.04 & & $<>$ & & 1.04 & & 1.03 & & 1.11 \\
\hline 5 & & 1.08 & & $<>$ & & 0.91 & & 0.91 & & $<>$ & & 1.03 & \\
\hline 6 & & & 1.07 & & 1.02 & & $<\mathrm{RR}>$ & & 1.01 & & 1.02 & & \\
\hline 7 & & & & 1.08 & & 1.01 & & 0.99 & & 1.05 & & & \\
\hline
\end{tabular}

Figure 10a.

\begin{tabular}{|c|c|c|c|c|c|c|c|c|c|c|c|c|c|}
\hline \multicolumn{14}{|c|}{ HEU EOC DSA } \\
\hline \multicolumn{14}{|c|}{ Upper Core } \\
\hline & A & B & C & D & $E$ & $\mathbf{F}$ & G & $\mathrm{H}$ & I & $\mathbf{J}$ & $\mathbf{K}$ & $\mathbf{L}$ & $\mathbf{M}$ \\
\hline & & & & \multicolumn{3}{|c|}{ COLD SOURCE } & & & & & & & \\
\hline 1 & & & & 1.01 & & 1.11 & & 1.17 & & 1.11 & & & \\
\hline 2 & & & 1.10 & & 1.12 & & $<>$ & & 1.14 & & 1.16 & & \\
\hline 3 & & 1.10 & & <> & & 1.07 & & 1.08 & & $<>$ & & 1.16 & \\
\hline 4 & 1.10 & & 1.04 & & 1.05 & & $<>$ & & 1.05 & & 1.03 & & 1.11 \\
\hline 5 & & 1.07 & & $<>$ & & 0.92 & & 0.90 & & $<>$ & & 1.03 & \\
\hline 6 & & & 1.06 & & 1.03 & & $<\mathrm{RR}>$ & & 1.00 & & 1.02 & & \\
\hline 7 & & & & 1.08 & & 1.01 & & 1.00 & & 1.07 & & & \\
\hline
\end{tabular}

Figure 10b.

\begin{tabular}{|c|c|c|c|c|c|c|c|c|c|c|c|c|c|}
\hline \multicolumn{14}{|c|}{$\%$ change from HEU EOC to HEU EOC DSA } \\
\hline \multicolumn{14}{|c|}{ Upper Core } \\
\hline & $\mathbf{A}$ & B & $\mathbf{C}$ & $\mathbf{D}$ & $\bar{E}$ & $\mathbf{F}$ & G & $\mathbf{H}$ & $\mathbf{I}$ & $\mathbf{J}$ & $\mathbf{K}$ & $\mathbf{L}$ & $\mathbf{M}$ \\
\hline & & & & \multicolumn{3}{|c|}{ COLD SOURCE } & & & & & & & \\
\hline 1 & & & & 0.9 & & 0.6 & & -0.4 & & -0.1 & & & \\
\hline 2 & & & 1.2 & & 0.8 & & $<>$ & & 0.3 & & -0.1 & & \\
\hline 3 & & 0.9 & & $<>$ & & -0.1 & & 0.6 & & $<>$ & & -0.4 & \\
\hline 4 & 0.2 & & 0.5 & & 1.1 & & $<>$ & & 0.9 & & 0.4 & & 0.0 \\
\hline 5 & & -0.1 & & $<>$ & & 0.6 & & -0.3 & & $<>$ & & 0.0 & \\
\hline 6 & & & -0.6 & & 0.3 & & $<\mathrm{RR}>$ & & -0.5 & & 0.8 & & \\
\hline 7 & & & & 0.6 & & -0.5 & & 0.4 & & 1.1 & & & \\
\hline
\end{tabular}

Figure 10c.

Figure 10. Radial power distribution for the upper half of the core for a.) HEU EOC, b.)HEU EOC DSA and c.) The percentage differences between the HEU EOC and the HEU EOC DSA 


\begin{tabular}{|c|c|c|c|c|c|c|c|c|c|c|c|c|c|}
\hline \multicolumn{14}{|c|}{ HEU EOC } \\
\hline \multicolumn{14}{|c|}{ Lower core } \\
\hline & $\mathbf{A}$ & B & $\mathbf{C}$ & $\mathbf{D}$ & $\bar{E}$ & $\mathbf{F}$ & $\mathbf{G}$ & $\mathbf{H}$ & I & $\mathbf{J}$ & $\mathbf{K}$ & $\mathbf{L}$ & $\mathbf{M}$ \\
\hline & & & & \multicolumn{3}{|c|}{ COLD SOURCE } & & & & & & & \\
\hline 1 & & & & 0.85 & & 0.93 & & 0.97 & & 0.91 & & & \\
\hline 2 & & & 0.99 & & 0.98 & & $<>$ & & 1.00 & & 1.02 & & \\
\hline 3 & & 1.02 & & $<>$ & & 0.96 & & 0.97 & & $<>$ & & 1.03 & \\
\hline 4 & 1.05 & & 0.96 & & 0.94 & & <> & & 0.92 & & 0.93 & & 1.02 \\
\hline 5 & & 1.01 & & $<>$ & & 0.82 & & 0.81 & & $<>$ & & 0.96 & \\
\hline 6 & & & 0.94 & & 0.90 & & $<R R>$ & & 0.88 & & 0.92 & & \\
\hline 7 & & & & 0.90 & & 0.87 & & 0.85 & & 0.89 & & & \\
\hline
\end{tabular}

Figure 11a.

\begin{tabular}{|c|c|c|c|c|c|c|c|c|c|c|c|c|c|}
\hline \multicolumn{14}{|c|}{ HEU EOC DSA } \\
\hline \multicolumn{14}{|c|}{ Lower core } \\
\hline & $\bar{A}$ & B & C & D & $\bar{E}$ & $\mathbf{F}$ & $\mathbf{G}$ & $\mathrm{H}$ & $I$ & J & $\mathbf{K}$ & $\mathbf{L}$ & $\mathbf{M}$ \\
\hline & & & & \multicolumn{2}{|c|}{ COLD SOURCE } & & & & & & & & \\
\hline 1 & & & & 0.84 & & 0.92 & & 0.97 & & 0.92 & & & \\
\hline 2 & & & 0.99 & & 0.97 & & $<>$ & & 1.00 & & 1.02 & & \\
\hline 3 & & 1.01 & & $<>$ & & 0.96 & & 0.96 & & $<>$ & & 1.03 & \\
\hline 4 & 1.04 & & 0.95 & & 0.93 & & $<>$ & & 0.92 & & 0.93 & & 1.02 \\
\hline 5 & & 1.00 & & $<>$ & & 0.82 & & 0.81 & & $<>$ & & 0.95 & \\
\hline 6 & & & 0.94 & & 0.90 & & $<\mathrm{RR}>$ & & 0.89 & & 0.92 & & \\
\hline 7 & & & & 0.90 & & 0.86 & & 0.85 & & 0.89 & & & \\
\hline
\end{tabular}

Figure 11b.

\begin{tabular}{|c|c|c|c|c|c|c|c|c|c|c|c|c|c|}
\hline \multicolumn{14}{|c|}{ \% change between HEU EOC and HEU EOC SDA } \\
\hline \multicolumn{14}{|c|}{ Lower core } \\
\hline & A & B & $\mathbf{C}$ & $\mathbf{D}$ & $E$ & $\mathbf{F}$ & $\mathbf{G}$ & $\mathbf{H}$ & $\mathbf{I}$ & $\mathbf{J}$ & $\mathbf{K}$ & $\mathbf{L}$ & $\mathbf{M}$ \\
\hline & & & & \multicolumn{2}{|c|}{ COLD SOURCE } & & & & & & & & \\
\hline 1 & & & & -0.7 & & -1.1 & & -0.5 & & 0.5 & & & \\
\hline 2 & & & 0.1 & & -0.9 & & $<>$ & & -0.1 & & -0.1 & & \\
\hline 3 & & -0.3 & & $<>$ & & -0.4 & & -0.4 & & $<>$ & & -0.2 & \\
\hline 4 & -1.0 & & -0.8 & & -1.2 & & $<>$ & & 0.4 & & -0.1 & & -0.3 \\
\hline 5 & & -0.8 & & $<>$ & & -0.3 & & -0.1 & & $<>$ & & -0.8 & \\
\hline 6 & & & -0.2 & & -0.5 & & $<\mathrm{RR}>$ & & 0.4 & & 0.3 & & \\
\hline 7 & & & & 0.4 & & -1.2 & & 0.2 & & -0.3 & & & \\
\hline
\end{tabular}

Figure 11c.

Figure 11. Radial power distribution for the lower half of the core for a.) HEU EOC, b.)HEU EOC DSA and c.) The percentage differences between the HEU EOC and the HEU EOC DSA 


\begin{tabular}{|l|l|l|l|l|l|l|l|l|l|l|l|l|l|l|}
\hline & $\mathbf{A}$ & $\mathbf{B}$ & $\mathbf{C}$ & $\mathbf{D}$ & $\mathbf{E}$ & $\mathbf{F}$ & $\mathbf{G}$ & $\mathbf{H}$ & $\mathbf{I}$ & $\mathbf{J}$ & $\mathbf{K}$ & $\mathbf{L}$ & $\mathbf{M}$ \\
\hline & & & & \multicolumn{2}{|c|}{ COLD SOURCE } & & & & & & & \\
\hline $\mathbf{1}$ & & & & 0.90 & & 1.01 & & 1.05 & & 0.93 & & & \\
\hline $\mathbf{2}$ & & & 0.91 & & 1.01 & & $<>$ & & 0.94 & & 0.78 & & \\
\hline $\mathbf{3}$ & & 0.71 & & $<>$ & & 0.97 & & 0.96 & & $<>$ & & 0.69 & \\
\hline $\mathbf{4}$ & 0.61 & & 0.73 & & 0.89 & & $<>$ & & 0.89 & & 0.74 & & 0.62 \\
\hline $\mathbf{5}$ & & 0.66 & & $<>$ & & 0.84 & & 0.85 & & $<>$ & & 0.69 & \\
\hline $\mathbf{6}$ & & & 0.72 & & 0.84 & & $<R R>$ & & 0.91 & & 0.87 & & \\
\hline $\mathbf{7}$ & & & & 0.89 & & 0.91 & & 0.94 & & 0.96 & & & \\
\hline
\end{tabular}

Figure 12a.

\begin{tabular}{|c|c|c|c|c|c|c|c|c|c|c|c|c|c|}
\hline \multicolumn{14}{|c|}{ LEU SU DSA } \\
\hline \multicolumn{14}{|c|}{ Upper Core } \\
\hline & A & B & C & D & $E$ & $F$ & $\mathbf{G}$ & $\mathrm{H}$ & I & $\mathrm{J}$ & $\mathbf{K}$ & $\mathbf{L}$ & M \\
\hline & & & & \multicolumn{3}{|c|}{ COLD SOURCE } & & & & & & & \\
\hline 1 & & & & 0.90 & & 1.01 & & 1.06 & & 0.95 & & & \\
\hline 2 & & & 0.92 & & 1.03 & & $<>$ & & 0.96 & & 0.82 & & \\
\hline 3 & & 0.75 & & $<>$ & & 0.99 & & 0.96 & & $<>$ & & 0.74 & \\
\hline 4 & 0.67 & & 0.77 & & 0.91 & & $<>$ & & 0.91 & & 0.76 & & 0.67 \\
\hline 5 & & 0.70 & & $<>$ & & 0.85 & & 0.86 & & $<>$ & & 0.71 & \\
\hline 6 & & & 0.76 & & 0.86 & & $<R R>$ & & 0.92 & & 0.87 & & \\
\hline 7 & & & & 0.91 & & 0.92 & & 0.94 & & 0.95 & & & \\
\hline
\end{tabular}

Figure 12b.

\begin{tabular}{|l|l|l|l|l|l|l|l|l|l|l|l|l|l|}
\hline & $\mathbf{A}$ & $\mathbf{B}$ & $\mathbf{C}$ & $\mathbf{D}$ & $\mathbf{E}$ & $\mathbf{F}$ & $\mathbf{G}$ & $\mathbf{H}$ & $\mathbf{I}$ & $\mathbf{J}$ & $\mathbf{K}$ & $\mathbf{L}$ & $\mathbf{M}$ \\
\hline & & & & \multicolumn{2}{|c|}{ COLD SOURCE } & & & & & & & \\
\hline $\mathbf{1}$ & & & & 0.3 & & 0.0 & & 0.9 & & 2.4 & & & \\
\hline $\mathbf{2}$ & & & 1.2 & & 2.6 & & $<>$ & & 2.1 & & 5.9 & & \\
\hline $\mathbf{3}$ & & 5.4 & & $<>$ & & 2.0 & & 0.2 & & $<>$ & & 7.1 & \\
\hline $\mathbf{4}$ & 9.7 & & 4.7 & & 2.2 & & $<>$ & & 1.4 & & 3.7 & & 7.9 \\
\hline $\mathbf{5}$ & & 6.5 & & $<>$ & & 1.8 & & 1.3 & & $<>$ & 2.8 & \\
\hline $\mathbf{6}$ & & & 5.2 & & 3.3 & & $<$ RR> & & 1.1 & & 0.2 & & \\
\hline $\mathbf{7}$ & & & & 1.9 & & 1.1 & & 0.0 & & -1.1 & & & \\
\hline
\end{tabular}

Figure 12c.

Figure 12. Radial power distribution for the upper half of the core for a.) LEU SU, b.) LEU SU DSA and c.) The percentage differences between the LEU SU and the LEU SU DSA 


\begin{tabular}{|c|c|c|c|c|c|c|c|c|c|c|c|c|c|}
\hline \multicolumn{14}{|c|}{ Lower core } \\
\hline & $\mathbf{A}$ & B & C & D & $E$ & $\mathbf{F}$ & $\mathbf{G}$ & $\mathrm{H}$ & I & J & $\mathbf{K}$ & $\mathbf{L}$ & M \\
\hline & & & & \multicolumn{3}{|c|}{ COLD SOURCE } & & & & & & & \\
\hline 1 & & & & 0.98 & & 1.09 & & 1.15 & & 1.05 & & & \\
\hline 2 & & & 1.18 & & 1.25 & & $<>$ & & 1.27 & & 1.19 & & \\
\hline 3 & & 1.20 & & $<>$ & & 1.35 & & 1.34 & & $<>$ & & 1.19 & \\
\hline 4 & 1.15 & & 1.21 & & 1.30 & & $<>$ & & 1.30 & & 1.18 & & 1.13 \\
\hline 5 & & 1.16 & & $<>$ & & 1.17 & & 1.16 & & <> & & 1.12 & \\
\hline 6 & & & 1.10 & & 1.13 & & $<\mathrm{RR}>$ & & 1.12 & & 1.10 & & \\
\hline 7 & & & & 1.00 & & 1.01 & & 1.00 & & 1.01 & & & \\
\hline
\end{tabular}

Figure 13a.

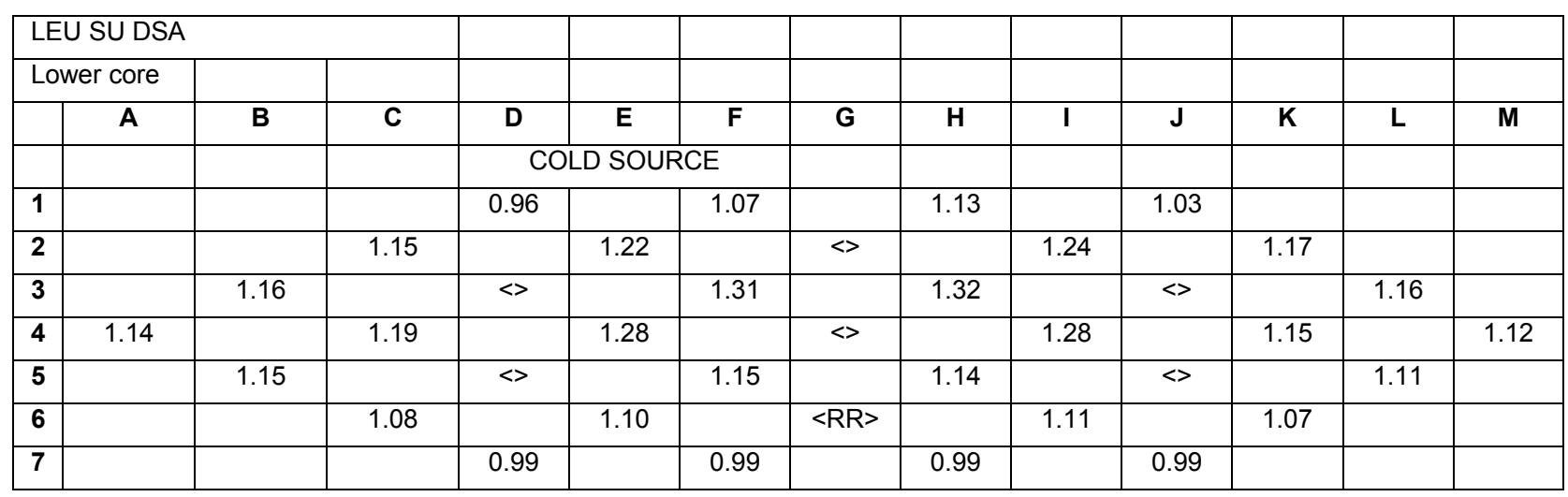

Figure 13b.

\begin{tabular}{|l|l|l|l|l|l|l|l|l|l|l|l|l|l|}
\hline & $\mathbf{A}$ & $\mathbf{B}$ & $\mathbf{C}$ & $\mathbf{D}$ & $\mathbf{E}$ & $\mathbf{F}$ & $\mathbf{G}$ & $\mathbf{H}$ & $\mathbf{I}$ & $\mathbf{J}$ & $\mathbf{K}$ & $\mathbf{L}$ & $\mathbf{M}$ \\
\hline & & & & \multicolumn{2}{|c|}{ COLD SOURCE } & & & & & & & \\
\hline $\mathbf{1}$ & & & & -1.1 & & -1.9 & & -2.1 & & -1.7 & & & \\
\hline $\mathbf{2}$ & & & -2.8 & & -2.3 & & $<>$ & & -2.2 & & -1.9 & & \\
\hline $\mathbf{3}$ & & -3.3 & & $<$ & & -2.5 & & -1.8 & & $<>$ & & -2.4 & \\
\hline $\mathbf{4}$ & -1.3 & & -1.7 & & -1.0 & & $<>$ & & -1.2 & & -2.5 & & -0.9 \\
\hline $\mathbf{5}$ & & -1.4 & & $<>$ & & -1.8 & & -1.3 & & $<>$ & & -1.0 & \\
\hline $\mathbf{6}$ & & & -1.2 & & -2.2 & & $<R R>$ & & -1.7 & & -2.7 & & \\
\hline $\mathbf{7}$ & & & & -1.0 & & -2.4 & & -1.1 & & -2.1 & & & \\
\hline
\end{tabular}

Figure 13c.

Figure 13. Radial power distribution for the lower half of the core for a.) LEU SU, b.)LEU SU DSA and c.) The percentage differences between the LEU SU and the LEU SU DSA 


\begin{tabular}{|c|c|c|c|c|c|c|c|c|c|c|c|c|c|}
\hline \multicolumn{14}{|c|}{ LEU EOC } \\
\hline \multicolumn{14}{|c|}{ Upper Core } \\
\hline & A & B & $\mathbf{C}$ & D & $\bar{E}$ & $\mathbf{F}$ & $\mathbf{G}$ & $\mathbf{H}$ & I & $\mathbf{J}$ & $\bar{K}$ & L & $\mathbf{M}$ \\
\hline & & & & \multicolumn{3}{|c|}{ COLD SOURCE } & & & & & & & \\
\hline 1 & & & & 0.93 & & 1.04 & & 1.09 & & 1.02 & & & \\
\hline 2 & & & 1.04 & & 1.11 & & $<>$ & & 1.13 & & 1.09 & & \\
\hline 3 & & 1.04 & & $<>$ & & 1.15 & & 1.15 & & $<>$ & & 1.10 & \\
\hline 4 & 1.02 & & 1.06 & & 1.14 & & $<>$ & & 1.14 & & 1.05 & & 1.03 \\
\hline 5 & & 1.05 & & $<>$ & & 1.05 & & 1.04 & & $<>$ & & 1.01 & \\
\hline 6 & & & 1.05 & & 1.06 & & $<\mathrm{RR}>$ & & 1.05 & & 1.01 & & \\
\hline 7 & & & & 1.03 & & 1.02 & & 1.01 & & 1.01 & & & \\
\hline
\end{tabular}

Figure 14a.

\begin{tabular}{|c|c|c|c|c|c|c|c|c|c|c|c|c|c|}
\hline \multicolumn{14}{|c|}{ LEU EOC DSA } \\
\hline \multicolumn{14}{|c|}{ Upper Core } \\
\hline & $\bar{A}$ & B & C & D & $E$ & $\mathbf{F}$ & $\mathbf{G}$ & $\mathrm{H}$ & $I$ & $\mathrm{~J}$ & $\mathbf{K}$ & $\mathrm{L}$ & M \\
\hline & & & & \multicolumn{3}{|c|}{ COLD SOURCE } & & & & & & & \\
\hline 1 & & & & 0.93 & & 1.04 & & 1.10 & & 1.03 & & & \\
\hline 2 & & & 1.05 & & 1.12 & & $<>$ & & 1.14 & & 1.10 & & \\
\hline 3 & & 1.05 & & $<>$ & & 1.17 & & 1.16 & & $<>$ & & 1.11 & \\
\hline 4 & 1.03 & & 1.07 & & 1.15 & & $<>$ & & 1.13 & & 1.06 & & 1.03 \\
\hline 5 & & 1.07 & & $<>$ & & 1.06 & & 1.05 & & $<>$ & & 1.01 & \\
\hline 6 & & & 1.06 & & 1.07 & & $\langle$ <RR $>$ & & 1.05 & & 1.01 & & \\
\hline 7 & & & & 1.04 & & 1.03 & & 1.02 & & 1.02 & & & \\
\hline
\end{tabular}

Figure 14b.

\begin{tabular}{|c|c|c|c|c|c|c|c|c|c|c|c|c|c|}
\hline \multicolumn{14}{|c|}{ \% change from LEU EOC to LEU EOC DSA } \\
\hline \multicolumn{14}{|c|}{ Upper Core } \\
\hline & A & B & $\mathbf{C}$ & $\mathbf{D}$ & $\bar{E}$ & $\mathbf{F}$ & $\mathbf{G}$ & $\mathbf{H}$ & $I$ & $\mathbf{J}$ & $\mathbf{K}$ & $\mathbf{L}$ & $\mathbf{M}$ \\
\hline & & & & \multicolumn{3}{|c|}{ COLD SOURCE } & & & & & & & \\
\hline 1 & & & & 0.3 & & -0.4 & & 0.3 & & 1.1 & & & \\
\hline 2 & & & 1.4 & & 0.8 & & $<>$ & & 0.6 & & 0.3 & & \\
\hline 3 & & 1.0 & & $<>$ & & 1.2 & & 0.4 & & $<>$ & & 1.5 & \\
\hline 4 & 1.2 & & 1.0 & & 0.9 & & $<>$ & & -0.1 & & 0.5 & & 0.8 \\
\hline 5 & & 1.2 & & $<>$ & & 0.3 & & 0.5 & & $<>$ & & 0.4 & \\
\hline 6 & & & 0.9 & & 0.4 & & $<R R>$ & & 0.0 & & -0.7 & & \\
\hline 7 & & & & 1.0 & & 0.6 & & 0.9 & & 0.6 & & & \\
\hline
\end{tabular}

Figure 14c.

Figure 14. Radial power distribution for the upper half of the core for a.) LEU EOC, b.)LEU EOC DSA and c.) The percentage differences between the LEU EOC and the LEU EOC DSA 


\begin{tabular}{|c|c|c|c|c|c|c|c|c|c|c|c|c|c|}
\hline \multicolumn{14}{|c|}{ LEU EOC } \\
\hline \multicolumn{14}{|c|}{ Lower core } \\
\hline & $\mathbf{A}$ & B & C & D & $E$ & $\mathbf{F}$ & $\mathbf{G}$ & $\mathbf{H}$ & $\mathbf{I}$ & $\mathbf{J}$ & $\mathrm{K}$ & $\mathbf{L}$ & $\mathbf{M}$ \\
\hline & & & & \multicolumn{3}{|c|}{ COLD SOURCE } & & & & & & & \\
\hline 1 & & & & 0.78 & & 0.86 & & 0.91 & & 0.84 & & & \\
\hline 2 & & & 0.94 & & 0.98 & & $<>$ & & 1.00 & & 0.97 & & \\
\hline 3 & & 0.98 & & $<>$ & & 1.04 & & 1.04 & & $<>$ & & 0.98 & \\
\hline 4 & 0.97 & & 0.98 & & 1.03 & & $<>$ & & 1.02 & & 0.96 & & 0.95 \\
\hline 5 & & 0.98 & & $<>$ & & 0.96 & & 0.95 & & $<>$ & & 0.94 & \\
\hline 6 & & & 0.94 & & 0.96 & & $<R R>$ & & 0.94 & & 0.91 & & \\
\hline 7 & & & & 0.87 & & 0.87 & & 0.86 & & 0.85 & & & \\
\hline
\end{tabular}

Figure 15a.

\begin{tabular}{|c|c|c|c|c|c|c|c|c|c|c|c|c|c|}
\hline \multicolumn{14}{|c|}{ LEU EOC DSA } \\
\hline \multicolumn{14}{|c|}{\begin{tabular}{|l|} 
Lower core \\
\end{tabular}} \\
\hline & $\mathbf{A}$ & B & C & D & $\bar{E}$ & $\mathbf{F}$ & G & $\mathrm{H}$ & 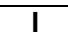 & $\mathbf{J}$ & $\mathbf{K}$ & $\mathbf{L}$ & $\mathbf{M}$ \\
\hline & & & & \multicolumn{3}{|c|}{ COLD SOURCE } & & & & & & & \\
\hline 1 & & & & 0.77 & & 0.85 & & 0.90 & & 0.83 & & & \\
\hline 2 & & & 0.94 & & 0.98 & & $<>$ & & 0.99 & & 0.97 & & \\
\hline 3 & & 0.97 & & $<>$ & & 1.03 & & 1.03 & & $<>$ & & 0.98 & \\
\hline 4 & 0.95 & & 0.97 & & 1.02 & & $<>$ & & 1.02 & & 0.96 & & 0.95 \\
\hline 5 & & 0.97 & & $<>$ & & 0.95 & & 0.94 & & $<>$ & & 0.94 & \\
\hline 6 & & & 0.93 & & 0.95 & & $<\mathrm{RR}>$ & & 0.93 & & 0.91 & & \\
\hline 7 & & & & 0.86 & & 0.86 & & 0.86 & & 0.86 & & & \\
\hline
\end{tabular}

Figure 15a.

\begin{tabular}{|c|c|c|c|c|c|c|c|c|c|c|c|c|c|}
\hline \multicolumn{14}{|c|}{$\%$ change from LEU EOC to LEU EOC DSA } \\
\hline \multicolumn{14}{|c|}{ Lower core } \\
\hline & $\mathbf{A}$ & B & C & D & $E$ & $F$ & $\mathbf{G}$ & $\mathrm{H}$ & $\mathrm{I}$ & $\mathbf{J}$ & $\mathbf{K}$ & $\mathbf{L}$ & M \\
\hline & & & & \multicolumn{3}{|c|}{ COLD SOURCE } & & & & & & & \\
\hline 1 & & & & -0.6 & & -0.9 & & -1.2 & & -0.6 & & & \\
\hline 2 & & & -0.3 & & -0.7 & & $<>$ & & -1.1 & & 0.1 & & \\
\hline 3 & & -1.1 & & $<>$ & & -1.1 & & -1.1 & & $<>$ & & -0.2 & \\
\hline 4 & -1.2 & & -1.7 & & -0.3 & & $<>$ & & 0.2 & & -0.5 & & -0.2 \\
\hline 5 & & -1.3 & & $<>$ & & -1.1 & & -1.3 & & $<>$ & & -0.5 & \\
\hline 6 & & & -1.1 & & -1.0 & & $<R R>$ & & -0.6 & & -0.2 & & \\
\hline 7 & & & & $\begin{array}{l}-1.2 \\
\end{array}$ & & -0.7 & & -0.2 & & 0.4 & & & \\
\hline
\end{tabular}

Figure 15a.

Figure 15. Radial power distribution for the lower half of the core for a.) LEU EOC, b.)LEU EOC DSA and c.) The percentage differences between the LEU EOC and the LEU EOC DSA 


\section{Three Dimensional Power Distributions}

To determine the hottest channels (highest local power density and fuel plate stripe with highest power) in the core, each fuel plate was divided into 42 square meshes with nominal dimensions of $2 \mathrm{~cm} \times 2 \mathrm{~cm}$, for a total of 42840 squares throughout the core. Each plate can then be considered as three vertical stripes of $\sim 2 \mathrm{~cm}$ width for a total of 3060 stripes throughout the core. MCNP was used to calculate the number of fissions within each square and it was assumed the energy deposited in each square was proportional to the number of fissions in each square.

The results of the three dimensional power distribution calculations for the equilibrium HEU and LEU cores were presented in [11]. To perform these calculations with reasonable statistics, $\sim 1.3 \times 10^{8}$ neutrons were followed during each set of calculations. The resulting power distributions were then used to find the peak power density and the peak stripe power as described below.

The relative power generated in each square was determined by normalizing the number of fissions in each square to the average number of fissions in each square over the entire core. The distributions were then determined by binning each relative power into bins with a width in relative power of 0.25 . The distributions are shown in Figures 16-19.

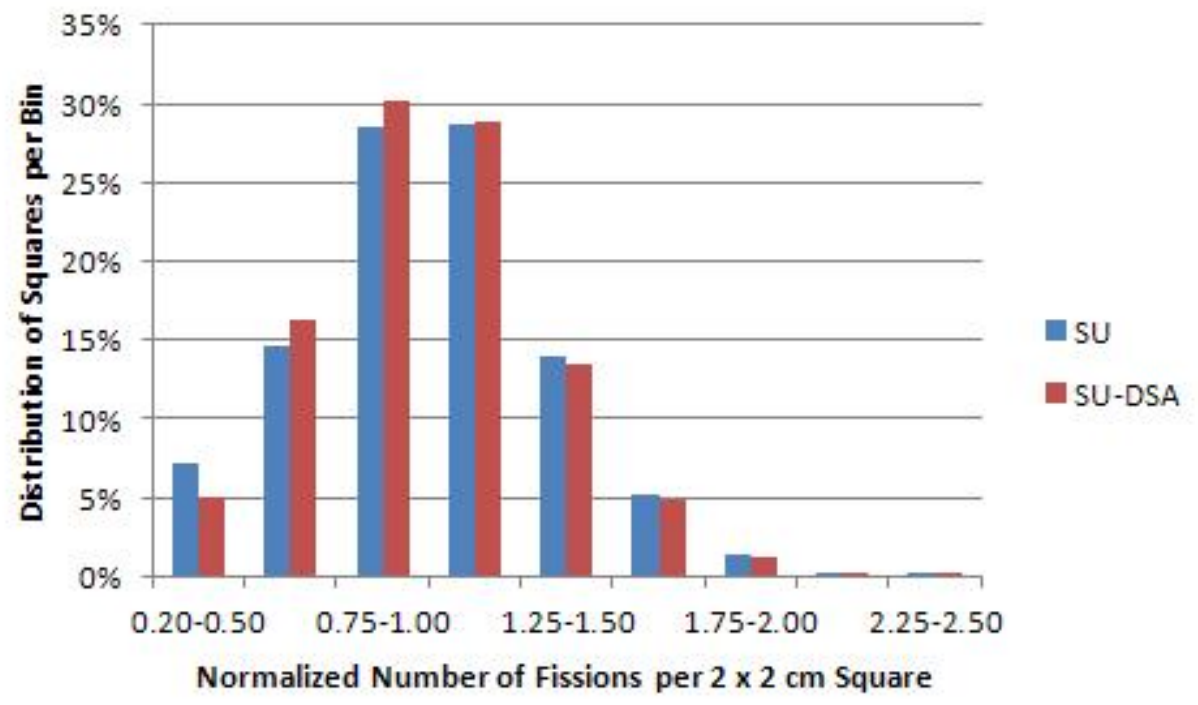

Figure 16. Local power distribution, HEU SU 


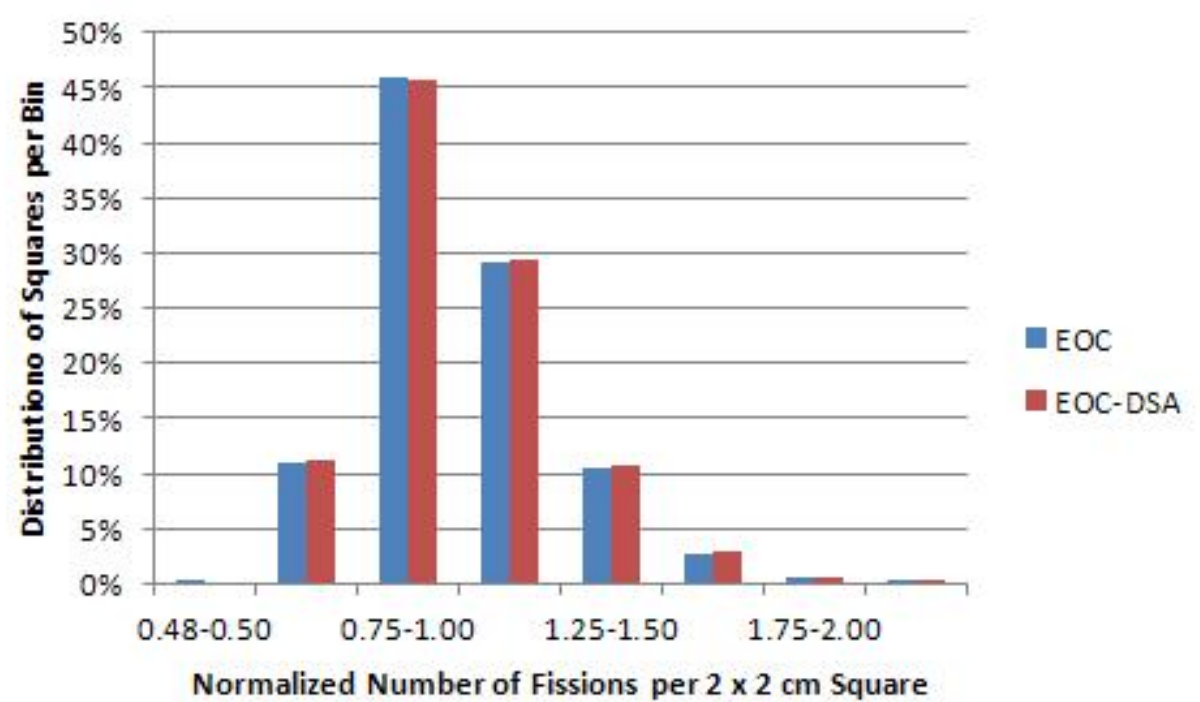

Normalized Number of Fissions per $2 \times 2 \mathrm{~cm}$ Square

Figure 17. Local power distribution, HEU EOC

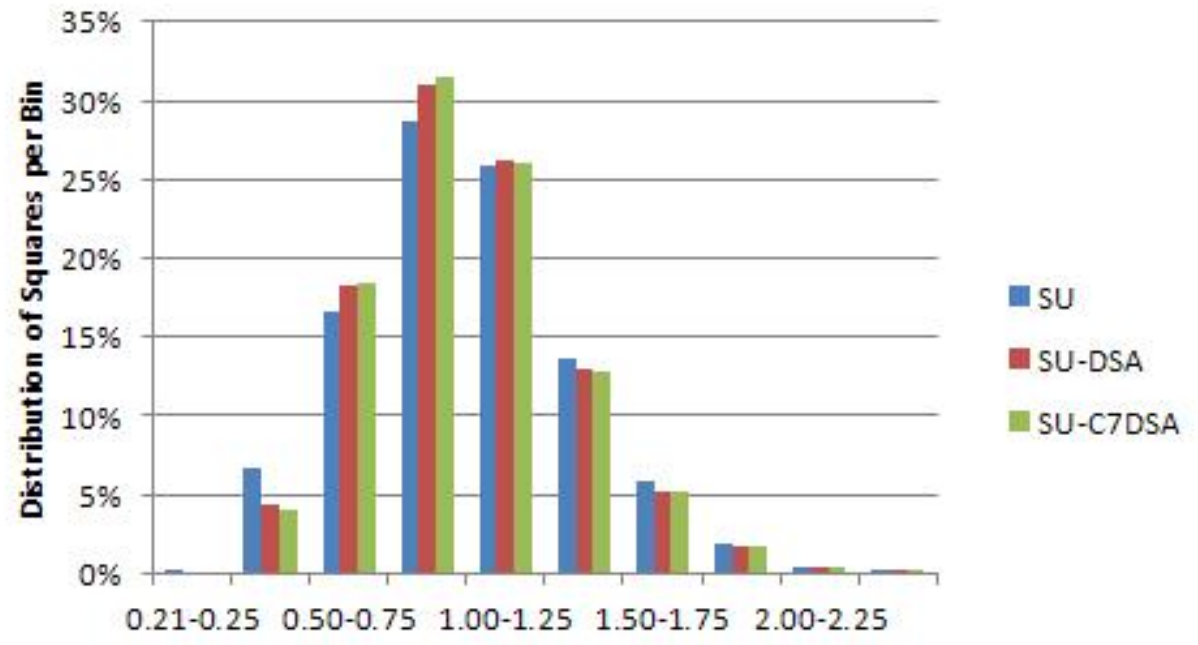

Normalized Number of Fissions per $2 \mathrm{~cm} \times 2 \mathrm{~cm}$ Square

Figure 18. Local power distribution, LEU SU 


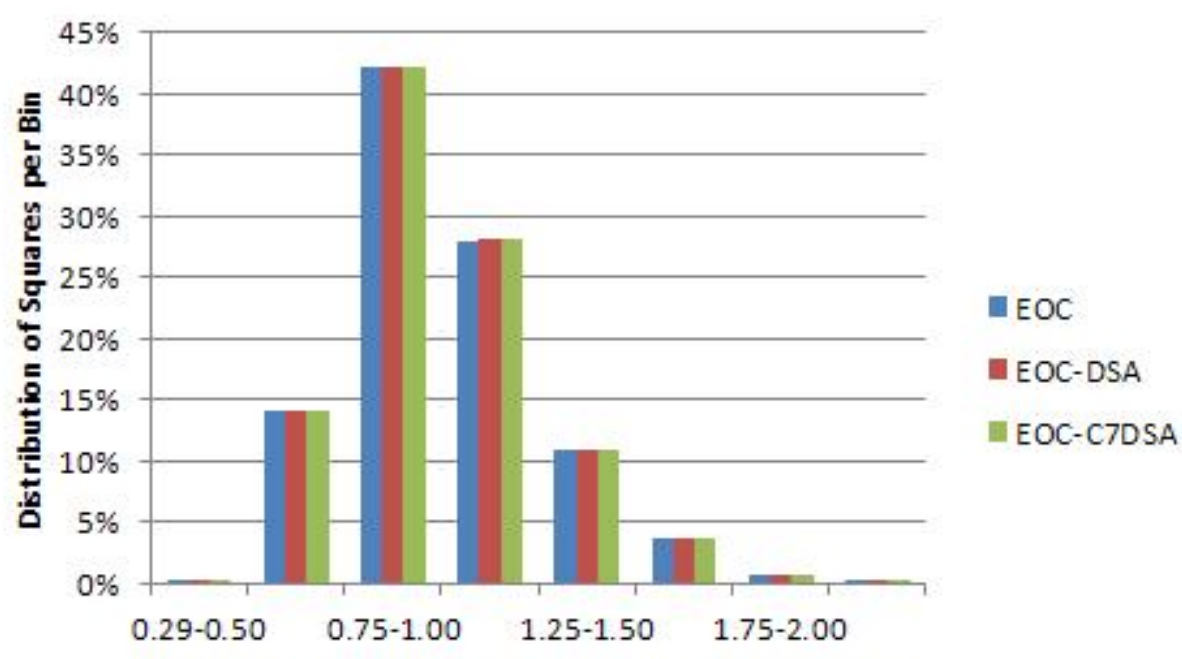

Normalized Number of Fissions per $2 \times 2 \mathrm{~cm}$ Square

Figure 19. Local power distribution, LEU EOC

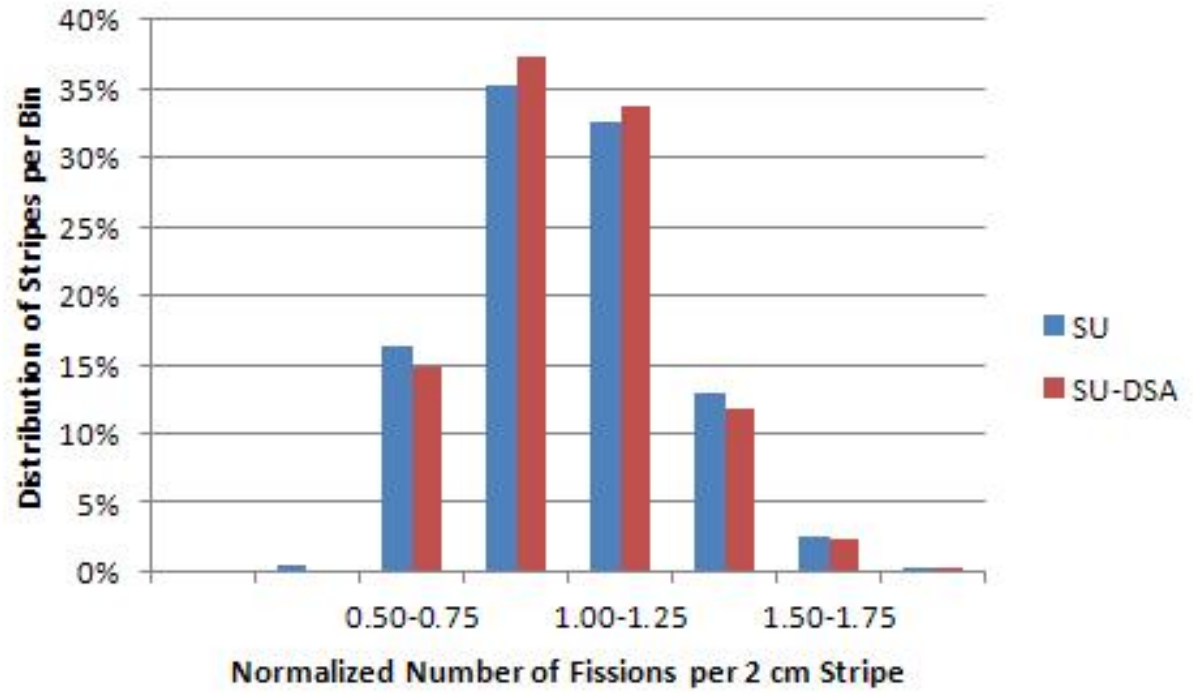

Figure 20. Stripe power distribution, HEU SU 


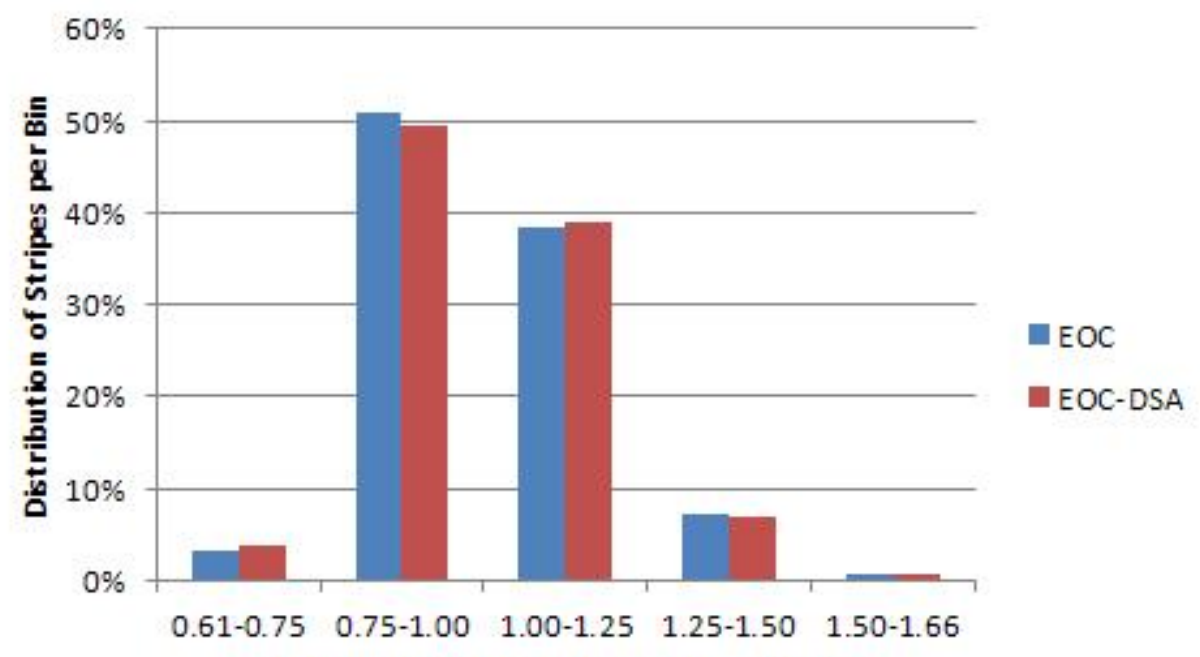

Normalized Number of Fissions per Stripe

Figure 21. Stripe power distribution, HEU EOC

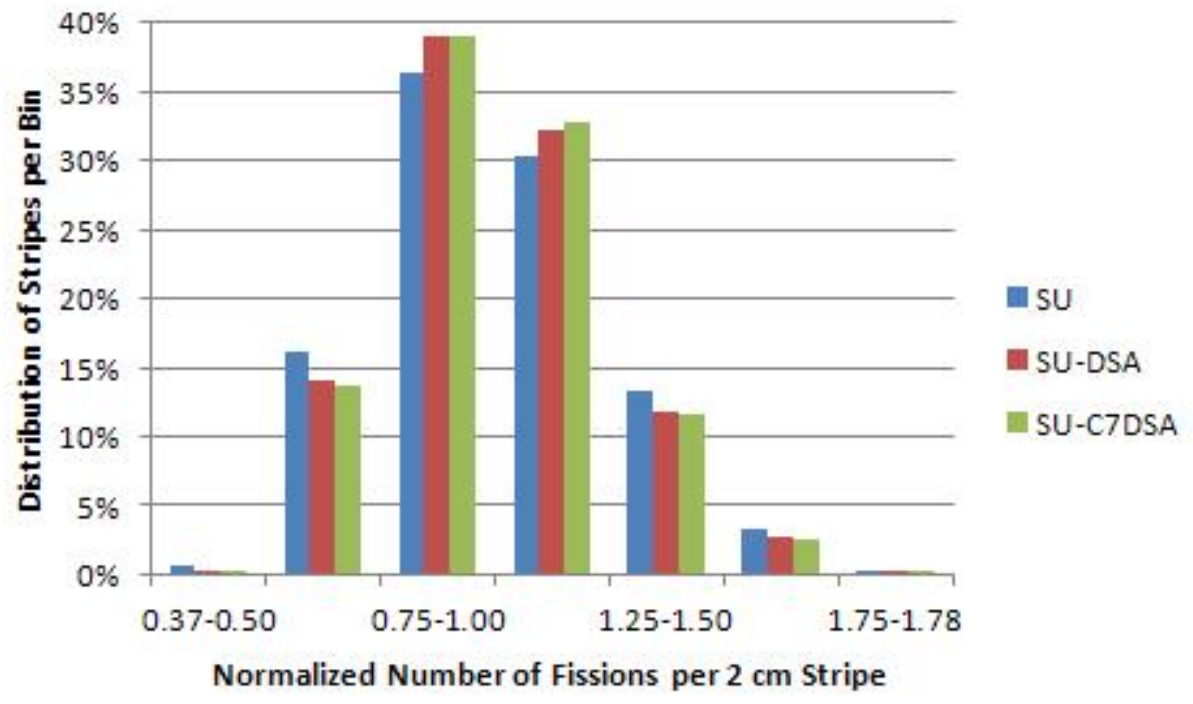

Figure 22. Stripe power distribution, LEU SU 


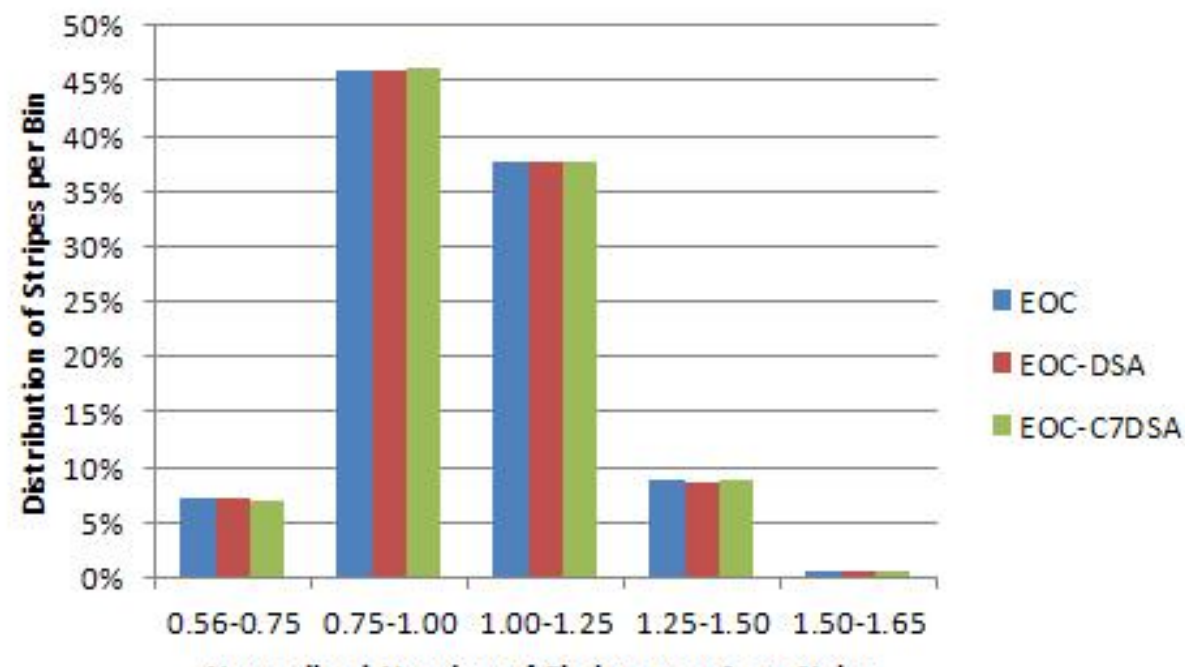

Normalized Number of Fissions per $2 \mathrm{~cm}$ Stripe

Figure 23. Stripe power distribution, LEU EOC

The number of fissions was determined for each $2 \mathrm{~cm}$ wide stripe by summing over the number of fissions within the squares that make up the stripe. Those data are presented in Figures 20-23. The location of the hottest spots may not be within the hottest stripes. The highest number of fissions (normalized to a core average of unity) along with their locations within the squares, stripes and half fuel elements are shown in Table 3. The calculated changes from using fresh shim arms to degraded shim arms are presented in Table 4. Table 4 demonstrates that the maximum change when using depleted shim arms for LEU fuel was $2.4 \%$. The analysis of the hottest points, stripes and half fuel elements shown in Figures 8-23 indicate that the hottest areas considered are not necessarily coincidental. The locations of the hottest point, stripe and half fuel element are also shown in Table 3 and indicate that those three hottest positions do not necessarily coincide. The results also indicate that there will not be any significant differences in the hottest points and stripes with HEU or LEU fuel when the shim arms are fresh or depleted. 
Table 3. Values and positions for the hottest points, stripes and half fuel elements. NA indicates no calculations with the C7SDA Cd distributions were made for the HEU fuel. The fuel element locations are shown in Figure 3 with $L$ representing the lower half of the fuel element and $U$ the upper half of the fuel element.

\begin{tabular}{|l|l|l|c|c|c|c|c|}
\hline & & SU & SU-DSA & SU-C7DSA & EOC & EOC-DSA & EOC-C7DSA \\
\hline HEU & Highest Point & 2.48 & 2.43 & NA & 2.19 & 2.21 & NA \\
\hline HEU & Highest Stripe & 1.81 & 1.78 & NA & 1.66 & 1.66 & NA \\
\hline HEU & Highest half-element & 1.28 & 1.26 & NA & 1.18 & 1.17 & NA \\
\hline LEU & Highest Point & 2.43 & 2.45 & 2.49 & 2.21 & 2.22 & 2.20 \\
\hline LEU & Highest Stripe & 1.78 & 1.74 & 1.76 & 1.65 & 1.65 & 1.65 \\
\hline LEU & Highest half-element & 1.35 & 1.32 & 1.31 & 1.15 & 1.17 & 1.16 \\
\hline & \multicolumn{7}{|c|}{ Location } \\
\hline HEU & Highest Point & H-1L & H-1L & NA & A-4U & M-4U & NA \\
\hline HEU & Highest Stripe & K-2L & K-2L & NA & H-1U & H-1U & NA \\
\hline HEU & Highest half-element & I-2L & I-2L & NA & H-1U & H-1U & NA \\
\hline LEU & Highest Point & K-2L & I-2L & I-2L & L-3U & L-3U & I-2U \\
\hline LEU & Highest Stripe & E-2L & E-2L & I-2L & H-1U & H-1U & H-1U \\
\hline LEU & Highest half-element & F-3L & H-3L & H-3L & H-3U & F-3U & H-3U \\
\hline
\end{tabular}

Table 4. Per cent change in highest point-wise power when comparing fresh and 25 cycle depleted shim arms.

\begin{tabular}{|l|c|c|}
\hline & Point & Stripe \\
\hline HEU SU SDA & $-2.2 \%$ & $-1.5 \%$ \\
\hline HEU EOC SDA & $0.7 \%$ & $-0.2 \%$ \\
\hline LEU SU SDA & $0.7 \%$ & $-2.0 \%$ \\
\hline LEU SU C7SDA & $2.4 \%$ & $-1.3 \%$ \\
\hline LEU EOC SDA & $0.6 \%$ & $0.2 \%$ \\
\hline LEU EOC C7SDA & $-0.5 \%$ & $0.2 \%$ \\
\hline
\end{tabular}

\section{Kinetics Parameters}

The values of neutron lifetime and delayed neutron fraction were calculated with MCNP5 for each of the fuels, core states and shim arm conditions. The results are shown in Table 5 and demonstrate that no significant changes in the kinetics parameters are to be expected because of shim arm depletion for either the HEU or the LEU fuel. 
Table 5. Calculation of the kinetics parameters for the different fuels, core states and shim arm conditions.

\begin{tabular}{|c|c|c|c|c|c|}
\hline Core & & Lifetime ( $\mu s)$ & $\sigma$ & $\begin{array}{l}\text { Delayed } \\
\text { neutron } \\
\text { fraction, }\end{array}$ & $\sigma$ \\
\hline HEU & SU & 698 & 1 & 0.00665 & 0.00005 \\
\hline $\mathrm{HEU}$ & SU - DSA & 701 & 1 & 0.00668 & 0.00006 \\
\hline HEU & EOC & 802 & 1 & 0.00662 & 0.00005 \\
\hline HEU & EOC-DSA & 806 & 1 & 0.00665 & 0.00009 \\
\hline LEU & SU & 651 & 1 & 0.00649 & 0.00005 \\
\hline LEU & SU - DSA & 653 & 1 & 0.00656 & 0.00005 \\
\hline LEU & SU-C7DSA & 654 & 1 & 0.00650 & 0.00005 \\
\hline LEU & EOC & 730 & 1 & 0.00649 & 0.00005 \\
\hline LEU & EOC-DSA & 733 & 1 & 0.00653 & 0.00005 \\
\hline LEU & EOC-C7DSA & 734 & 1 & 0.00650 & 0.00005 \\
\hline
\end{tabular}

\section{Summary}

This report details the predicted effects of shim arm depletion on the shim arm worth, the shutdown margin, power distributions, and kinetics parameters. The effects of shim arm depletion were determined for both the present HEU fuel and the proposed U10Mo LEU fuel. Analyses were performed for the startup and the end-of-cycle equilibrium states. The distribution of cadmium depletion for the HEU fuel was determined using models for the present HEU fuel in the NBSR. The distribution of cadmium depletion for the LEU fuel was not determined for the LEU fuel in the present designed geometry. A set of distributions was determined for the U10Mo fuel when it was designed to be in a different geometry, the fuel being 7 inches long (the COMP7 design) vs. the present 11 inches. In order to estimate the effects of shim arm depletion on the power distributions for the LEU fuel, the Cd distributions from the analyses of the HEU and the COMP7 analyses were used. The two different distributions of cadmium depletion used with the LEU resulted in peak powers that were similar to the peaking when fresh shim arms were used.

The effects of the depletion on the shim arm worth was determined and demonstrates that the shim arm worth is lower for the LEU fuel than it is for the HEU fuel, not only before the shim arm depletion but also after the shim arm depletion. The change in the worth of the shim arms after depletion is larger for the LEU core than it is for the present HEU core. The life expectancy of the shim arms for the LEU fuel is expected to be the same as currently used for the HEU core, namely, that they will function properly for 25 cycles before replacement. 
The power distributions considered include the average power over each half fuel element, the power generated in $2 \mathrm{~cm}$ wide stripes of each fuel plate and the power generated in $2 \times 2 \mathrm{~cm}$ squares of each fuel plate. The analyses show that the hottest spots in the core are not necessarily located in the hottest stripes or in the hottest half fuel elements. Likewise the hottest stripes in the core are not necessarily related to the hottest half fuel elements. Even though the position of the hottest areas of the core changed with depleted shim arms when compared to fresh shim arms, there was only minor change in the magnitude of the power generated in the hottest areas.

Lastly, there were no significant changes in the kinetics parameters calculated when the shim arms are depleted.

\section{References}

1. NIST, http://www.ncnr.nist.gov/resources/n-lengths/list.html, National Institutue of Standards and Technology Center for Neutron Research, Gaithersburg, MD, November 1999.

2. NNDC, J.K. Tuli, "Nuclear Wallet Cards", fifth edition, , Brookhaven National Laboratory, Upton, NY, July, 1995.

3. NIST, "Technical Specifications for the NIST Test Reactor (NBSR)," Appendix A, License No. TR-5, National Institutue of Standards and Technology, Gaithersburg, MD, 2009.

4. A.L. Hanson, D.J. Diamond, and R.E. Williams, "Depletion of the Cadmium Shim Arms in the NBSR", memo to files, Brookhaven National Laboratory, Upton, NY, November 2005.

5. A.L. Hanson and D.J. Diamond, "Depletion of the Cadmium Shim Arms in the NBSR for the COMP7 LEU Core", memo to files, Brookhaven National Laboratory, Upton, NY, July 28, 2009.

6. X-5 Monte Carlo Team, "MCNP - A General Monte Carlo N-Particle Transport Code, Version 5", LA-UR-03-1987, Los Alamos National Laboratory, Los Alamos, NM, April 24, 2003.

7. L. Cheng, A. Hanson, D. Diamond, J. Xu, J. Carew, and D. Rorer, "Physics and Safety Analysis for the NIST Research Reactor", BNL-NIST-0803, Rev. 1, Brookhaven National Laboratory, Upton, NY, April, 2004.

8. D.I. Poston and H.R. Trellue, "MONTEBURNS, Version 2.0," Los Alamos National Laboratory, Los Alamos, NM, updated Dec. 2, 2002.

9. S. Ludwig, "Revision to ORIGEN2-Version 2.2," Oak Ridge National Laboratory, Oak Ridge, TN, May 23, 2002. 
10. A.L. Hanson and D.J. Diamond, "Determination of Inventories and Power Distributions for the NBSR," Brookhaven National Laboratory, Upton, NY, April 27, 2005.

11. A.L. Hanson and D.J. Diamond, "Calculation of Design Parameters for an Equilibrium LEU Core in the NBSR", BNL-96386-2011-IR, Brookhaven National Laboratory, Upton, NY, September 29, 2011. 